\title{
Regulation of Synapse Development by Vgat Deletion from ErbB4-Positive Interneurons
}

\author{
Thiri W. Lin, ${ }^{1 \star}$ Zhibing Tan, ${ }^{1,3 *}$ Arnab Barik, ${ }^{1}$ Dong-Min Yin, ${ }^{1}$ Egil Brudvik, ${ }^{1}{ }^{\oplus}$ Hongsheng Wang, ${ }^{1,3}$ \\ Wen-Cheng Xiong, ${ }^{1,2,3,4}$ and $\mathbb{\complement}^{-}$Lin Mei ${ }^{1,2,3,4}$ \\ ${ }^{1}$ Department of Neuroscience and Regenerative Medicine, Medical College of Georgia, Augusta University, Augusta, Georgia 30912, ${ }^{2}$ Charlie Norwood VA \\ Medical Center, Augusta, Georgia 30904, ${ }^{3}$ Department of Neurosciences, School of Medicine, Case Western Reserve University, Cleveland, Ohio 44106, and \\ ${ }^{4}$ Louis Stokes Cleveland Veterans Affairs Medical Center, Cleveland, Ohio 44106
}

GABA signaling has been implicated in neural development; however, in vivo genetic evidence is missing because mutant mice lacking GABA activity die prematurely. Here, we studied synapse development by ablating vesicular GABA transporter (Vgat) in ErbB4 ${ }^{+}$interneurons. We show that inhibitory axo-somatic synapses onto pyramidal neurons vary from one cortical layer to another; however, inhibitory synapses on axon initial segments (AISs) were similar across layers. Conversely, parvalbumin-positive $\left(\mathrm{PV}^{+}\right) / \mathrm{ErbB}^{+}{ }^{+}$interneurons and PV-only interneurons receive a higher number of inhibitory synapses from $\mathrm{PV}^{+}$ErbB4 ${ }^{+}$interneurons compared with ErbB4-only interneurons. Vgat deletion from ErbB4 ${ }^{+}$interneurons reduced axo-somatic or axo-axonic synapses from $\mathrm{PV}^{+} \mathrm{ErbB}^{+}{ }^{+}$interneurons onto excitatory neurons. This effect was associated with corresponding changes in neurotransmission. However, the Vgat mutation seemed to have little effect on inhibitory synapses onto $\mathrm{PV}^{+}$and/or ErbB4 ${ }^{+}$interneurons. Interestingly, perineuronal nets, extracellular matrix structures implicated in maturation, survival, protection, and plasticity of $\mathrm{PV}^{+}$interneurons, were increased in the cortex of ErbB4-Vgat ${ }^{-1-}$ mice. No apparent difference was observed between males and females. These results demonstrate that Vgat of ErbB4 ${ }^{+}$interneurons is essential for the development of inhibitory synapses onto excitatory neurons and suggest a role of GABA in circuit assembly.

Key words: axo-axonic; axo-somatic; ErbB4; GABA; inhibition; parvalbumin

Significance Statement

GABA has been implicated in neural development, but in vivo genetic evidence is missing because mutant mice lacking GABA die prematurely. Here, we ablated Vgat in ErbB4 ${ }^{+}$interneurons in an inducible manner. We provide evidence that the formation of inhibitory and excitatory synapses onto excitatory neurons requires Vgat in interneurons. In particular, inhibitory axo-somatic and axo-axonic synapses are more vulnerable. Our results suggest a role of GABA in circuit assembly.

\section{Introduction}

GABAergic interneurons, comprising $15-20 \%$ of total neurons in the brain, are critical for brain functions by controlling neuronal

\footnotetext{
Received March 10, 2017; revised Jan. 22, 2018; accepted Jan. 29, 2018

Author contributions: T.W.L., W.-C.X., and L.M. designed research; T.W.L., Z.T., A.B., D.-M.Y., E.B., and H.W. performed research; T.W.L. and Z.T. analyzed data; T.W.L. and L.M. wrote the paper.

This work was supported by grants from the National Institutes of Health (L.M., W.-C.X.) and the Department of Veterans Affairs (L.M., W-C.X.). We thank Dr. A. Stranahan (Augusta University) for training with Reconstruct software; Dr. K. Dhandapani (Augusta University) for the PSD-95 antibody; Dr. D. Cai (University of Michigan) and Dr. J. Rathfon (Nikon) for consultation and advice on confocal imaging and analysis; Dr. J. Albert (Case Western Reserve University) and Dr. H.Xu (Augusta University) for consultation and helpful discussions on post hoc power calculation; Mei and Xiong laboratory members for helpful discussions and assistance; and J. Klein for drawing the mouse diagram.

The authors declare no competing financial interests.

*T.W.L. and Z.T. contributed equally to this work.

Correspondence should be addressed to Lin Mei, Department of Neurosciences, School of Medicine, Case Western Reserve University, 10900 Euclid Ave., Cleveland, 0H 44106. E-mail: lin.mei@case.edu.

DOI:10.1523/JNEUROSCI.0669-17.2018

Copyright $\odot 2018$ the authors $\quad 0270-6474 / 18 / 382533-18 \$ 15.00 / 0$
}

excitability, integration of synaptic inputs, and oscillations of cortical networks (Isaacson et al., 2011; Tremblay et al., 2016). They are remarkably diverse in morphology, physiological properties, and function (Markram et al., 2004; Klausberger et al., 2008; Le Magueresse et al., 2013; Kepecs et al., 2014). GABAergic transmission is thought to regulate circuit formation in the brain (Owens et al., 2002; Le Magueresse et al., 2013). In the visual cortex, knock-down of Gad1 (GAD67, glutamic acid decarboxylase, a major enzyme that synthesizes GABA) or reducing excitability in individual parvalbumin-positive $\left(\mathrm{PV}^{+}\right)$basket cells decreased axon branching and axo-somatic innervations onto pyramidal neurons in organotypic slices (Chattopadhyaya et al., 2007; Baho et al., 2012). Conversely, knock-down of Vgat (vesicular GABA transporter, critical for loading GABA into synaptic vesicles) or expressing TeNT-Lc (tetanus toxin light chain) to eliminate presynaptic release in $\mathrm{PV}^{+}$neurons increased axon branching and the number of axonal boutons onto pyramidal neuron somas in organotypic slices in the visual cortex (Baho et al., 2012; Wu et al., 
2012). However, in vivo genetic evidence is missing for the role of GABAergic transmission in neural development because null mutant mice without important molecules in the GABA pathway die prematurely due to cleft palate or respiratory failure (Asada et al., 1997; Homanics et al., 1997; Ji et al., 1999; Wojcik et al., 2006; Saito et al., 2010). ErbB4 is a transmembrane tyrosine kinase that serves as a receptor for the trophic factor neuregulin 1 . They both are risk genes of mental disorders including schizophrenia, bipolar disorder, and depression in various populations (Mei et al., 2014). Neuregulin 1 and ErbB4 play a role in the assembly of the GABAergic circuitry (Flames et al., 2004; Krivosheya et al., 2008; Fazzari et al., 2010; Ting et al., 2011; Del Pino et al., 2013; Yin, Chen et al., 2013) and have been implicated in neurotransmission and synaptic plasticity (Woo et al., 2007; Fazzari et al., 2010; Wen et al., 2010; Y. J. Chen et al., 2010; Del Pino et al., 2013; Yin, Chen et al., 2013; Yin, Sun et al., 2013; Lu et al., 2014).

In this study, we attempted to determine whether and how neural development is altered by GABA transmission during postnatal development. To avoid embryonic lethality, we took advantage of the Erbb4 promoter that is active in 68\% of GAD67positive neurons in the cortex (Bean et al., 2014). The utilization of the inducible CreER line Erbb4-Cre-ERT2 enabled targeting at the postnatal stage, a period that is critical for synapse formation, axon pruning, and circuit refinement in mice (Rakic et al., 1986; Chattopadhyaya et al., 2004; Chattopadhyaya et al., 2007; Doischer et al., 2008; Kilb, 2012; Le Magueresse et al., 2013; Inan et al., 2014), and this avoided confounding factors such as altered neuron migration in result interpretation. As proof of principle, this study focused on synapse development and refinement in the cortex because ErbB4 in this region is present solely in GABA neurons. We show that the number of inhibitory axo-somatic synapses onto pyramidal neurons is layer specific; however, inhibitory synapses on the axon initial segments (AISs) do not vary much from layer to layer. We have also characterized inhibitory synapses onto excitatory neurons formed by interneurons that are positive only for PV or ErbB4 (PV-only and ErbB4-only, respectively), inhibitory-inhibitory synapses formed by these three groups of interneurons $\left(\mathrm{PV}^{+} \mathrm{ErbB}^{+}, \mathrm{PV}\right.$-only, and ErbB4-only) and excitatory synapses. Importantly, we provide first in vivo genetic evidence that the formation of inhibitory and excitatory synapses in the brain requires GABA release from interneurons. In particular, inhibitory axo-somatic and axo-axonic synapses onto excitatory neurons are more sensitive to Vgat deletion than inhibitory synapses onto inhibitory neurons. These results suggest a role of GABA in synapse formation and circuit development.

\section{Materials and Methods}

Mice. Erbb4-2A-CreERT2 (Erbb4 ${ }^{\text {CreER }}$, Jax 012360) (Madisen et al., 2010), Rosa-LSL-tdTomato (Ai9, Jax 007905) (Madisen et al., 2010), Vgat-loxP (Vgat ${ }^{\mathrm{f} / \mathrm{fl}}$, Jax 012897) (Tong et al., 2008), and Thy1-GFP-S (Jax 011070) (Feng et al., 2000) mice were purchased from The Jackson Laboratory. Mice were housed at $23^{\circ} \mathrm{C}$ with $12 \mathrm{~h} / 12 \mathrm{~h}$ light/dark cycle with rodent chow (Diet 1/4 7097; Harlan Teklad) available ad libitum. No apparent differences were observed between males and females. Both male and female mice were used except for in vivo EEG recordings, for which only male mice were used. Animal handling and experimental procedures were approved by the Institutional Animal Care and Use Committee of Augusta University.

Tamoxifen (Tam) administration. Mice were administered intraperitoneally with $100 \mathrm{mg} / \mathrm{kg}$ Tam once at postnatal day 10 (P10), P12, and $\mathrm{P} 14$. This treatment paradigm was found to obtain healthy mice while effectively inducing the expression of tdTomato in Erbb4 ${ }^{\text {CreER }}$; Ai9 mice (control) and the ablation of Vgat in Erbb4 ${ }^{\mathrm{CreER}} ; \mathrm{Vgat}^{\mathrm{f} / \mathrm{f}} ; \mathrm{Ai9}$ mice (ErbB4Vgat $\left.^{-l-}\right)$. To induce sparse recombination in Erbb4 ${ }^{\mathrm{CreER}} ; \mathrm{Vgat}^{\mathrm{fl} / \mathrm{fl}} ; \mathrm{Ai9}$ mice, $25 \mathrm{mg} / \mathrm{kg}$ Tam was administered once at P10.
Western blot analysis. Brain tissues were dissected in ice-cold $1 \times$ PBS buffer and homogenized in RIPA buffer containing the following (in mm): 50 Tris- $\mathrm{HCl}, \mathrm{pH}$ 7.4, $150 \mathrm{NaCl}, 2$ EDTA, 1 PMSF, 50 sodium fluoride, 1 sodium vanadate, and 1 DTT with 1 sodium deoxycholate, $1 \%$ SDS, and $1 \%$ protease inhibitor mixture. Samples were resolved on SDS/PAGE and transferred to nitrocellulose membranes (1620112; BioRad), which were incubated in the TBS buffer containing $0.1 \%$ Tween 20 and $5 \%$ milk for $1 \mathrm{~h}$ at $22-25^{\circ} \mathrm{C}$ before the addition of primary antibody for incubation overnight at $4^{\circ} \mathrm{C}$. After washing, the membranes were incubated with the HRP-conjugated secondary antibody (Life Technology) in the same TBS buffer for $1 \mathrm{~h}$ at $22-25^{\circ} \mathrm{C}$. Immunoreactive bands were visualized using enhanced chemiluminescence (Pierce). Films were scanned with an Epson 1680 scanner and analyzed with ImageJ. Band density of proteins of interest was normalized in relation to GAPDH control.

EEG recording. Control and ErbB4-Vgat ${ }^{-1-}$ mice at $\mathrm{P} 30$ were anesthetized with ketamine/xylazine $(0.1 \mathrm{ml} / 10 \mathrm{~g}$ body weight). EEG recording electrodes were placed above dura of sensory cortex $(2 \mathrm{~mm}$ posterior, $3 \mathrm{~mm}$ lateral, with bregma as a reference point) and fixed with screws to the skull without punching the dura. One screw at cerebellum served as the ground electrode. Electrodes and screws were secured to the skull with dental cement. Mice were allowed to recover for $>5 \mathrm{~d}$ before recording in a box with ad libitum access to food and water. EEG signals were collected with a differential bio-amplifier (FE136; AD Instruments) and digitized with a PowerLab system (AD Instruments). Signals were sampled at $1 \mathrm{kHz}$ with $0.3 \mathrm{~Hz}$ high-pass filter and $100 \mathrm{~Hz}$ low-pass filter. Each mouse was recorded for $>2 \mathrm{~h}$ each day for up to 2 weeks. Epilepsy-related EEG $(0.5-40 \mathrm{~Hz})$ power spectrum density was calculated using Fourier transform in LabChart (AD Instruments).

Immunohistochemistry. Anesthetized mice were perfused transcardially with cold $4 \%$ paraformaldehyde (PFA) in $0.1 \mathrm{~m}$ phosphate buffer. Brains were dissected out and incubated in $4 \%$ PFA at $4^{\circ} \mathrm{C}$ for $4-8 \mathrm{~h}$ and washed in $1 \times$ PBS for 8-12 h. They were incubated one night each in $15 \%$ and in $30 \%$ sucrose in PBS at $4^{\circ} \mathrm{C}$ for dehydration. Brain blocks were frozen and sliced with the cryostat (HM550; Thermo Scientific) into $40 \mu \mathrm{m}$ sections for most immunofluorescence procedures except experiments with Thy1-GFP mice, for which $100 \mu \mathrm{m}$ sections were used. Sections could be saved at $-20^{\circ} \mathrm{C}$ in cryoprotectant solution (FD Neurotechnologies) or used immediately. They were permeabilized with $0.3 \%$ Triton X-100 and 5\% BSA or $10 \%$ donkey serum in TBS for $1 \mathrm{~h}$ and incubated at $4^{\circ} \mathrm{C}$ overnight with primary antibodies in $0.15 \%$ Triton X-100 and 5\% BSA or 10\% donkey serum in TBS. After washing with TBS for $10 \mathrm{~min} 3$ times, samples were incubated with secondary antibodies for $1-2 \mathrm{~h}$ at room temperature. Brain sections were washed in TBS for $10 \mathrm{~min}$ 4 times at room temperature and mounted with SlowFade Diamond Antifade Mountant (catalog \#S36972; Thermo Fisher).

Confocal microscopy and quantitative imaging analysis. Quantification analyses were done by an investigator blinded to genotypes. S1 of the somatosensory cortex was analyzed. Image processing and data quantifications were performed with the Fiji version of ImageJ (https://fiji.sc/\#) (Schindelin et al., 2012). To quantify the cell number, single $Z$-plane images were acquired with a $20 \times / 0.75$ numerical aperture $(\mathrm{NA})$ objective (Plan Apo; Nikon) at $1024 \times 1024$ pixel image size, $0.62 \mu \mathrm{m} /$ pixel with the pinhole set at 1.0 Airy disc unit and densities were calculated. To analyze VGAT punctae, single $Z$-plane images were acquired with a $60 \times 1$ 1.4 NA oil-immersion objective (Plan Apochromat; Nikon) at $1024 \times$ 1024 pixel image size, $0.04 \mu \mathrm{m} /$ pixel with the pinhole set at 1.0 Airy disc unit. VGAT intensity of punctae colocalized or not colocalized with ErbB4 ${ }^{+}$ boutons in regions of interest (ROIs) was measured. Background intensity for each image was averaged and subtracted. Mean fluorescence intensity was calculated and presented in arbitrary units. The number of VGAT punctae that were colocalized with ErbB4 ${ }^{+}$boutons and total ErbB4 ${ }^{+}$ boutons were quantified in set ROIs.

To quantify $\mathrm{PV}^{+}, \mathrm{ErbB}^{+}{ }^{+}$, or $\mathrm{PV}^{+} \mathrm{ErbB}^{+}$boutons onto somas of excitatory or inhibitory neurons, $Z$-plane images of individual somas were acquired with a $60 \times / 1.4$ NA oil-immersion objective (Plan Apochromat; Nikon), $0.4 \mu \mathrm{m}$ steps, $5 \times$ zoom at $512 \times 512$ pixel image size, $0.08 \mu \mathrm{m} /$ pixel with the pinhole set at 1.0 Airy disc unit. To quantify $\mathrm{PV}^{+}$, ErbB4 ${ }^{+}$, or $\mathrm{PV}^{+} \mathrm{ErbB}^{+}{ }^{+}$boutons onto AISs, $Z$-plane images of individual AISs were acquired with a $60 \times / 1.4$ NA oil-immersion objective (Plan 
Apochromat; Nikon), $0.4 \mu \mathrm{m}$ steps, $4 \times$ zoom at $512 \times 512$ pixel image size, $0.1 \mu \mathrm{m} /$ pixel with the pinhole set at 1.0 Airy disc unit. Image stacks were rendered in Vaa3D, a 3D visualization-assisted analysis tool (Peng et al., 2010) that allows for interactive rotation, to generate 3D volumetric images. Individual presynaptic boutons in contact with the somas or AISs were marked and quantified using the $3 \mathrm{D}$ marker tool. Boutons at sizes between 0.2 and $3 \mu \mathrm{m}^{2}$ were counted. The $Z$-thickness of $3 \mathrm{D}$ volumetric images was adjusted or zoomed in to ensure that only marked boutons in contact with somas or AISs were accounted and quantified once. The following synaptic markers were used: GAD67 and SYT2 as presynaptic markers of inhibitory synapses; gephyrin and $\mathrm{GABA}_{\mathrm{A}} \mathrm{R}-\alpha 1$ as postsynaptic markers of inhibitory synapses; vesicular glutamate transporter 1 (VGLUT-1,) as presynaptic marker of excitatory synapses; and PSD-95 as postsynaptic marker of excitatory synapses. Single $Z$-plane images were acquired as described for VGAT punctae (see above). To establish ErbB4 ${ }^{+}$ and $\mathrm{PV}^{+}$boutons represent as GABAergic synapse-forming terminals, GAD67 and gephyrin were used. GAD67 ${ }^{+}$boutons, defined as $0.5-1 \mu \mathrm{m}^{2}$ axonal varicosities that were in contact with outlined somas, were quantified. Gephyrin punctae above a set threshold that were in contact or partially overlap with ErbB4 ${ }^{+}$boutons were quantified. VGLUT-1 punctae above a set threshold that were in contact or partially overlap with $\mathrm{PV}^{+}$and/or ErbB4 ${ }^{+}$somas were quantified. VGLUT-1 appeared to be an authentic marker of excitatory synapses because $>96 \%$ of these punctae were in contact or partially overlap with PSD-95 punctae at the ErbB4 ${ }^{+}$interneuron somas. To quantify inhibitory synapses onto interneurons, $\mathrm{SYT}^{+}{ }^{+}$boutons that were in contact with somas of $\mathrm{PV}^{+}$ and/or ErbB4 ${ }^{+}$interneurons were quantified. More than $97 \%$ of SYT2 ${ }^{+}$ boutons were in contact or partially overlap with $\mathrm{GABA}_{\mathrm{A}} \mathrm{R}-\alpha 1$, indicating that SYT2 was a marker of inhibitory synapses.

To quantify the number of Wisteria floribunda agglutinin (WFA)-labeled interneurons, images were acquired with a $10 \times / 0.45$ NA objective (Plan Apo; Nikon) at $1024 \times 1024$ pixel image size, $1.24 \mu \mathrm{m} /$ pixel with the pinhole set at 1.0 Airy disc unit. WFA intensity was measured at the $Z$-plane of widest soma area from image stacks of the whole soma covered by WFA. Background intensity for each image was averaged and subtracted. Mean fluorescence intensity was calculated and presented in arbitrary units.

To quantify the dendritic spines of pyramidal neurons, images were acquired with a $60 \times / 1.4$ NA oil-immersion objective (Plan Apochromat; Nikon), $0.5 \mu \mathrm{m}$ steps, $4 \times$ zoom at $512 \times 512$ pixel image size, 0.10 $\mu \mathrm{m} /$ pixel with the pinhole set at 1.0 Airy disc unit. To characterize dendrites of pyramidal neurons, images were captured with a $20 \times / 0.75 \mathrm{NA}$ objective (Plan Apo; Nikon), $1.0 \mu \mathrm{m}$ steps, $512 \times 512$ pixel image size, $1.24 \mu \mathrm{m} /$ pixel with the pinhole set at 1.0 Airy disc unit. 3D-reconstructed images were obtained by using Reconstruct software version 1.1.0.0 (Fiala, 2005) (http://synapses.clm.utexas.edu) to quantify dendritic length and complexity. Sholl analysis was done by implementing a plug-in for Fiji (http://imagej.net/Sholl_Analysis). Diameter concentric circles at $10 \mu \mathrm{m}$ steps were used to reveal the number of dendritic intersections.

Electrophysiology. Control and ErbB4-Vgat ${ }^{-1-}$ mice (P30-P35) were anesthetized with isoflurane and subjected to cardiac perfusion with ice-cold oxygenated $\left(95 \% \mathrm{O}_{2}\right.$ and $\left.5 \% \mathrm{CO}_{2}\right)$ artificial cerebrospinal fluid (ACSF) containing the following (in $\mathrm{mM}$ ): 110 choline $\mathrm{Cl}, 3.5 \mathrm{KCl}, 0.5 \mathrm{CaCl}_{2}, 7$ $\mathrm{MgCl}_{2}, 1.3 \mathrm{NaH}_{2} \mathrm{PO}_{4}, 25 \mathrm{NaHCO}_{3}$, and 20 glucose. Brains were removed rapidly and placed in ice-cold oxygenated ACSF. The sensory cortex was dissected, transverse slices $(250-300 \mu \mathrm{M})$ were cut on a vibratome (VT1200; Leica) and allowed to recover at $32^{\circ} \mathrm{C}$ for $1 \mathrm{~h}$ before recording. The ACSF used for recovery and recording contained the following (in mM): 125 $\mathrm{NaCl}, 3.5 \mathrm{KCl}, 2 \mathrm{CaCl}_{2}, 1.3 \mathrm{MgCl}_{2}, 1.3 \mathrm{NaH}_{2} \mathrm{PO}_{4}, 25 \mathrm{NaHCO}_{3}$, and 10 glucose. Individual slices were transferred to a submerged recording chamber and continuously perfused with the ACSF $(3.0 \mathrm{ml} / \mathrm{min})$ at $32^{\circ} \mathrm{C}$. Slices were visualized under a microscope (IX51WI; Olympus) using infrared video microscopy and differential interference contrast optics.

$\mathrm{ErbB}_{4}{ }^{+}$interneurons were identified with the expression of tdTomato. Pyramidal neurons were identified based on their location and shape and were morphologically verified by biocytin-backfilling. The patch electrodes were made from borosilicate glass capillaries (B-120-6915 ; Sutter Instruments) with a resistance in the range of 2.5-4 M $\Omega$. The internal solution for $\mathrm{mEPSC}$ and action potential recording contained the following (in mM): $125 \mathrm{~K}$-gluconate, $15 \mathrm{KCl}, 10 \mathrm{HEPES}, 4 \mathrm{MgCl} 2,4$
Na2ATP, 0.4 Na3GTP, 10 Tris-phosphocreatine, 0.2 EGTA, and 0.3\% biocytin. TTX $(1 \mu \mathrm{M})$ and bicuculline $(10 \mu \mathrm{M})$ were added to the recording ACSF to block action potential and GABAergic transmission, respectively. AP frequency-intensity curves were obtained by injecting $2 \mathrm{~s}$ step currents ( -50 to $400 \mathrm{pA}$ ), with each step at $50 \mathrm{pA}$ and interstep interval of $20 \mathrm{~s}$. The internal solution for mIPSC recording contained the following (in mM): $100 \mathrm{CsCH}_{3} \mathrm{SO}_{3}, 40 \mathrm{CsCl}, 10 \mathrm{HEPES}, 4$ $\mathrm{MgCl}_{2}, 4 \mathrm{Na}_{2} \mathrm{ATP}, 0.4 \mathrm{Na}_{3} \mathrm{GTP}, 10$ Tris-phosphocreatine, $0.2 \mathrm{EGTA}$, and $0.3 \%$ biocytin. TTX $(1 \mu \mathrm{M})$, CNQX $(20 \mu \mathrm{M})$, and DL-AP5 $(50 \mu \mathrm{M})$ were added to the recording ACSF to block action potential and glutamatergic transmission, respectively. Recordings were made with an Axon 700A patch-clamp amplifier and 1320A interface (Molecular Devices). The signals were filtered at $2 \mathrm{kHz}$ using amplifier circuitry, sampled at $10 \mathrm{kHz}$ and analyzed using Clampex 9.0 (Molecular Devices).

Antibodies. All antibodies were used for immunofluorescence studies unless stated otherwise. The following antibodies were used in this study: Vgat mouse monoclonal (1:500, Western blot, catalog \#131 111, SYSY); PV mouse monoclonal (1:1000, catalog \#235; Swant); PV rabbit polyconal (1:1000, catalog \#PV 25; Swant); gephyrin mouse monoclonal (1:300, catalog \#147 011, SYSY); NeuN mouse monoclonal (1:500, catalog \#M022122; Neuromis); ankyrin-G (1:10, catalog \#73-146; NeuroMab); Vglut-1 guinea pig polyclonal (1:1000, catalog \#AB5905; Millipore); SYT2 mouse monoclonal (1:200, catalog \#znp-1-c; DSHB); GABA ${ }_{\mathrm{A}} \mathrm{R}-\sigma 1$ rabbit polyclonal (1:1000, catalog \#AB5592; Millipore), PSD-95 rabbit polyclonal (1:100, catalog \#2507; Cell Signaling Technology), and lectin from Wisteria floribunda (1:200, catalog \#L1516; Sigma-Aldrich). Secondary antibodies were stored in $50 \%$ glycerol at $-20^{\circ} \mathrm{C}$. Alexa Fluorconjugated secondary antibody-488 or -647 (1:200 final concentration) against mouse IgG, rabbit IgG, and guinea pig IgG were used accordingly (Jackson ImmunoResearch Laboratories).

Statistics. Statistical analysis was done using GraphPad Prism 6.0 software. Two-tailed unpaired $t$ test was used to compare data between control and ErbB4-Vgat ${ }^{-1-}$ mice and, in some cases, to compare superficial and deep cortical layers in controls. One-way ANOVA followed by Tukey's multiple-comparisons test was used to evaluate layer-specific differences in control mice. For analysis of frequency-intensity $(F-I)$ curves, two-way ANOVA followed by Bonferroni's post hoc test was used. Data of cumulative probability were analyzed with Kolmogorov-Smirnov test. No statistical methods were used to predetermine sample sizes, but our sample sizes were either more or similar to those commonly used in similar experiments in the literature (Chattopadhyaya et al., 2004; Chattopadhyaya et al., 2007; Baho et al., 2012; Wu et al., 2012). Post hoc power calculated from the observed data was obtained using $\mathrm{G}^{\star}$ Power software (Faul et al., 2009). We observed post hoc power results ranging from 0.6 to $1(60-100 \%)$, which would suggest that there is a $60-100 \%$ chance of detecting a statistical difference and a $40-0 \%$ chance of making a type II error, incorrectly accepting the null hypothesis. Investigators of imaging analysis, electrophysiology, and EEG experiments were blinded to genotypes of mice. One pair of control and mutant mice were tested on a given day and which one was tested first was random. No data points were excluded. Data are represented as means \pm SEM. $p<0.05$ is considered significant.

\section{Results}

\section{Generation and characterization of ErbB $4^{+}$neuron-specific Vgat mutant mice}

Null mutants of Gad1 or Vgat die in the embryonic stage, which prevents studies of GABA's role during development. To solve this problem, we generated a mutant mouse in which Vgat is ablated specifically in ErbB4 ${ }^{+}$interneurons. VGAT is the GABA transporter that loads GABA into synaptic vesicles in GABAergic interneurons and is critical for GABA transmission (Fon et al., 2001; Wojcik et al., 2006). Vgat-loxP $\left(\right.$ Vgat $\left.^{\mathrm{fl} / \mathrm{fl}}\right)$ mice (Tong et al., 2008) (Jax 012897) were crossed with Erbb4-Cre-ERT2 (Erbb4 ${ }^{\mathrm{CreER}}$ ) mice (Madisen et al., 2010) (Jax 012360) to generate Erbb4 ${ }^{\text {CreER; }}$ $V g a t t^{\mathrm{t} / \mathrm{l}}$ mice (Fig. 1A). In Erbb4 ${ }^{\mathrm{CreER}}$ mice, the Cre-ERT2 cassette is inserted downstream of the Erbb4 locus and does not alter the expression of endogenous ErbB4 (Madisen et al., 2010; Bean et 
A

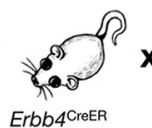<smiles>[V]</smiles>

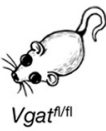

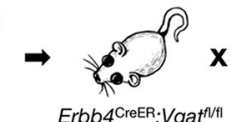
Erbb4CreER;Vgatint

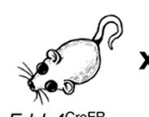

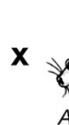
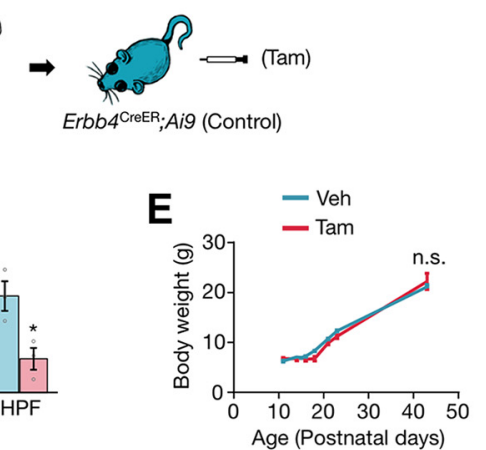

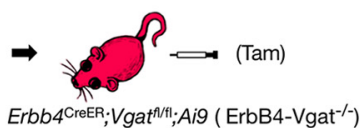

B
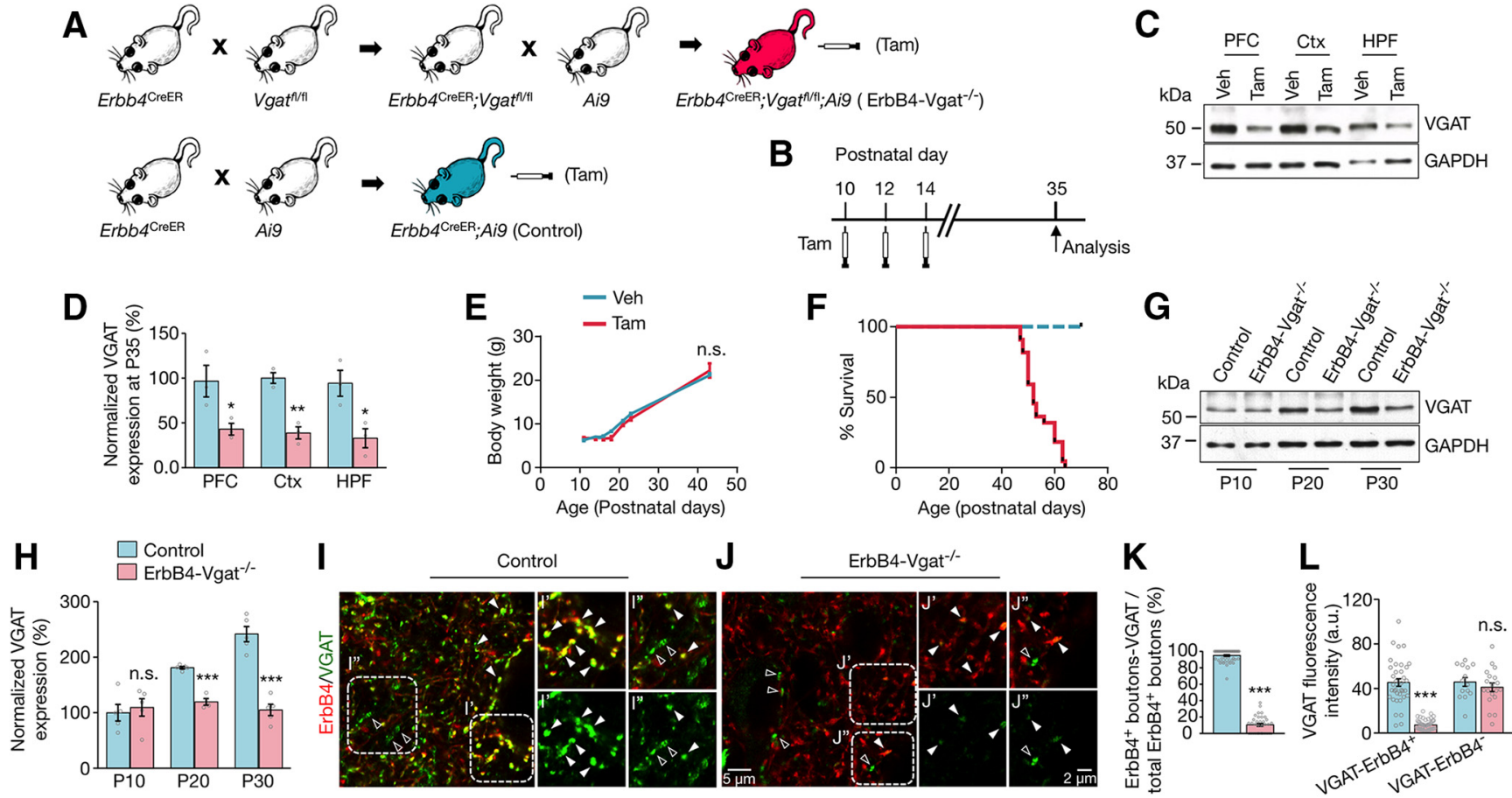

Figure 1. Elimination of GABA transmission from ErbB4 ${ }^{+}$interneurons during postnatal development. $A$, Genetic strategy for postnatal ablation of $V g a t$ in ErbB4 ${ }^{+}$interneurons. Erbb4 $4^{\text {CreeR }}$ and ${ }_{\text {Erbb4 }}{ }^{\text {CreER }}$,Vgat ${ }^{\mathrm{f} / \mathrm{fl}}$ mice were crossed with $L S L$-tdTomato (Aig) mice to visualize ErbB4 ${ }^{+}$neurons. $\boldsymbol{B}$, Tam administration and experimental timeline. $\boldsymbol{C}$, Reduced VGAT in the brain tissues of Tam-treated Erbb4 ${ }^{\text {CreER}} ; \mathrm{Vgat} / \mathrm{flfl}$ mice compared with vehicle-treated controls at P35. D, Quantitative data of $\boldsymbol{C}(n=3$ mice per group, PFC: $p=0.04 ;$ (tx: $p=0.003 ; \mathrm{HPF}: p=0.03)$. $\boldsymbol{E}$, Comparable growth rate of vehicle- and Tam-treated Erbb4 ${ }^{\mathrm{CreER}}, \mathrm{Vgat}{ }^{\mathrm{fl} / \mathrm{fl}}$ mice. $\boldsymbol{F}$, Kaplan-Meier survival curves of control and ErbB4-Vgat ${ }^{-I-}$ mice $(n=21$ and 22 mice, respectively). G, VGAT reduction in ErbB4-Vgat ${ }^{-I-}$ mice. $\boldsymbol{H}$, Quantitative data of $\boldsymbol{G} . \boldsymbol{I}, \boldsymbol{J}$, Representative coronal sections were immunolabeled with antibody against VGAT. Higher magnification of dotted areas is shown in images on the right (ErbB4, red; VGAT, green). Closed arrowheads indicate VGAT punctae colocalized with ErbB4 ${ }^{+}$boutons; open arrowheads indicate VGAT punctae not colocalized with ErbB4 ${ }^{+}$boutons. $\boldsymbol{K}$, Decreased number of VGAT punctae associated with ErbB4 ${ }^{+}$boutons in ErbB4-Vgat ${ }^{-1-}$ mice. Control, $n=46$ ROls, 9 sections, 3 mice; ErbB4-Vgat ${ }^{-1-}, n=35$ R0ls, 9 sections, 4 mice. $L$, Decreased VGAT intensity in ErbB4 ${ }^{+}$, but not ErbB4 ${ }^{-}$(ErbB4-negative), boutons in ErbB4-Vgat ${ }^{-l-}$ mice. VGAT-ErbB4 ${ }^{+}:$control, $n=36$ ROls, 9 sections, 3 mice; ErbB4-Vgat ${ }^{-l-}, n=20$ ROls, 9 sections, 4 mice. VGAT-ErbB4-: control, $n=14$ ROls, 9 sections, 3 mice; ErbB4-Vgat ${ }^{-1-}, n=19$ ROls, 9 sections, 4 mice. PFC, Prefrontal cortex; Ctx, cortex; HPF, hippocampal formation. Error bars indicate SEM. n.s., Not significant. ${ }^{*} p<0.05 ;{ }^{* *} p<0.01 ;{ }^{* * *} p<0.001$.

al., 2014). Because of the 2A oligopeptide between ErbB4 and Cre-ERT2 that mediates ribosomal skip, ErbB4 and Cre-ER are expressed as individual proteins. ER is a mutant human estrogen receptor that binds the synthetic ligand tamoxifen (Tam), but not endogenous estrogen. Mice were treated with Tam or vehicle (corn oil) three times beginning at P10 (Fig. 1B), which deletes exon 2 of the Vgat gene and causes a frame shift mutation and thus abolishes Vgat expression in ErbB4 ${ }^{+}$interneurons. Tam treatment of Erbb4 ${ }^{\mathrm{CreER}} ; V_{g a t}{ }^{\mathrm{f} / \mathrm{fl}}$ mice caused a reduction in VGAT protein in the prefrontal cortex, cortex, and hippocampus compared with vehicle-treated $E r b b 4^{\mathrm{CreER}} ; V_{g a t}{ }^{\mathrm{fl} / \mathrm{fl}}$ mice (Fig. $1 C, D$ ). Tam had no effect on growth rate (Fig. $1 E$ ), but mice developed spontaneous seizures beginning at $\mathrm{P} 45$ and died before P70 (Fig. $1 F$ ).

To visualize ErbB4 ${ }^{+}$neurons, Erbb4 ${ }^{\mathrm{CreER}}$ mice and $\mathrm{Erbb} 4^{\mathrm{CreER}}$; $V g a t^{\mathrm{fl} / \mathrm{ll}}$ mice were crossed with Rosa::LSL-tdTomato (Ai9) mice in which tdTomato expression is suppressed by a lox-stop-lox cassette that could be released by Tam treatment (Madisen et al., 2010; Bean et al., 2014) (Fig. 1A). Unless otherwise indicated (Fig. $1 C-F)$, Tam-treated Erbb4 ${ }^{\mathrm{CreER}} ; V_{g a t}{ }^{\mathrm{fl} / \mathrm{fl}} ; A i 9$ mice are referred to as ErbB4-Vgat ${ }^{-1-}$ mice and control mice as Tam-treated Erbb4 ${ }^{\mathrm{CreER}}$;Ai9 mice (Fig. 1A). Although there were no consistent data about the effects of Tam on neural development, both control and Vgat mutant mice were treated with Tam to eliminate a possible confounding effect. VGAT expression in the cortex increased postnatally (Fig. $1 G, H$ ), in agreement with previous findings (Minelli et al., 2003); however, this increase was blocked in ErbB4-Vgat $^{-1-}$ mice (Fig. 1G,H). A significant reduction was observed as early as P20 (10 d after Tam treatment). Immunostaining revealed that VGAT was absent in $89 \%$ of ErbB $4^{+}$boutons (Fig. $1 \mathrm{~K})$. In the remaining $11 \%$ in which VGAT was detected, its intensity was reduced by $84 \%$, compared with control mice (Fig. $1 L$ ). The intensity of ErbB4 ${ }^{-}$VGAT punctae was not changed in ErbB4Vgat $^{-l-}$ mice (Fig. $1 L$ ). These results demonstrate that VGAT ablation was specific for ErbB4 ${ }^{+}$interneurons.

Noninvasive in vivo EEG recording was conducted to determine whether ErbB4-Vgat ${ }^{-1-}$ mice had electrographic seizure activity before behavioral seizures. As shown in Figure 2, they did not exhibit epileptiform activity before P46. Therefore, we focused on the mice at P35, a time when the development of GABAergic and glutamatergic systems is completed (Chattopadhyaya et al., 2004; Chattopadhyaya et al., 2007; Doischer et al., 2008; Okaty et al., 2009) and before electrographic or behavioral seizures manifested.

\section{No effect of postnatal Vgat knock-out on numbers of} pyramidal neurons, $\mathrm{PV}^{+}$interneurons, and ErbB4 ${ }^{+}$ interneurons

$\mathrm{PV}^{+}$and $\mathrm{ErbB} 4{ }^{+}$interneurons are generated primarily in the medial ganglionic eminence and the central ganglionic eminence at the embryonic stage (Flames et al., 2004; Liodis et al., 2007; Butt et al., 2008; Choi et al., 2010; Gelman et al., 2010). They migrate tangentially to populate different layers of the cortex by the first postnatal week (Miyoshi et al., 2011; Marin, 2013). ErbB4 is expressed in migrating interneurons and believed to be important for populating the cortex (Yau et al., 2003; Flames et al., 2004). Conversely, the radial migration of glutamatergic pyramidal neurons that were born in the ventricular zone is completed by birth 
A

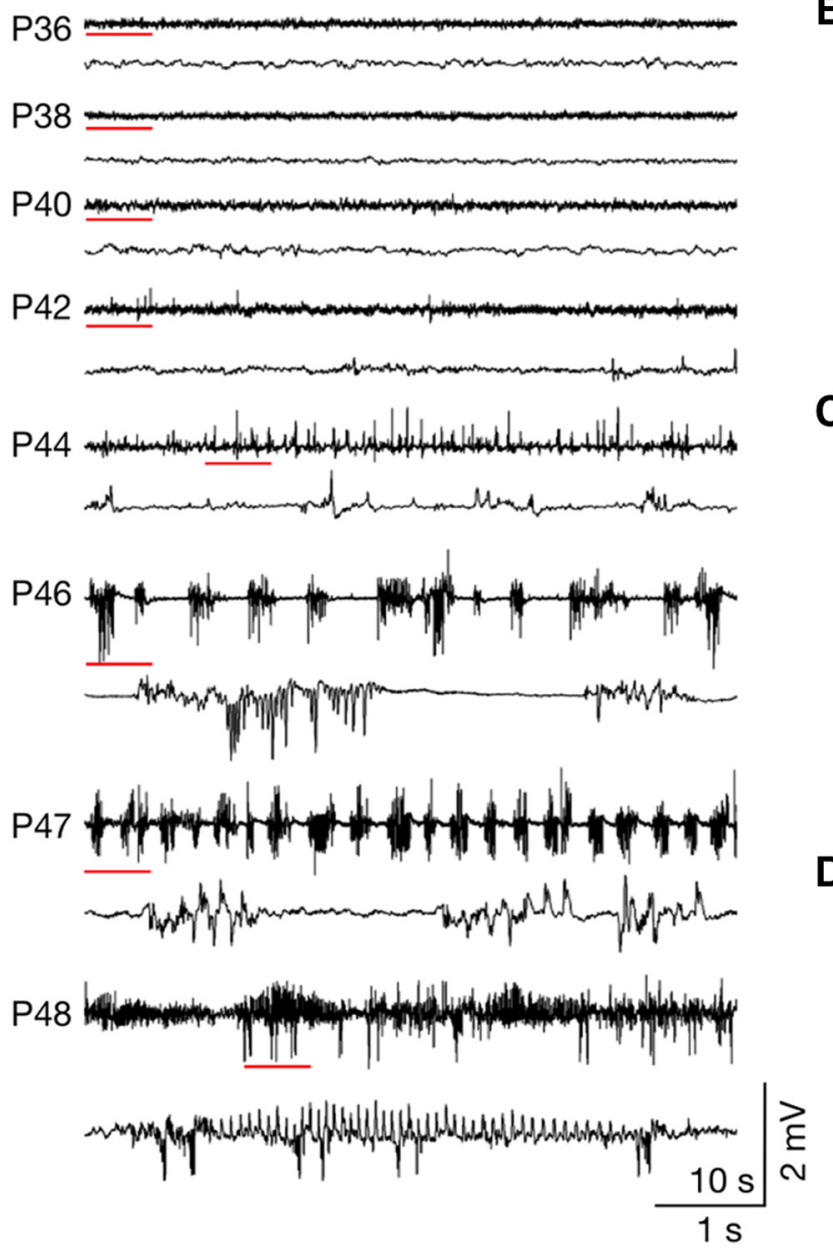

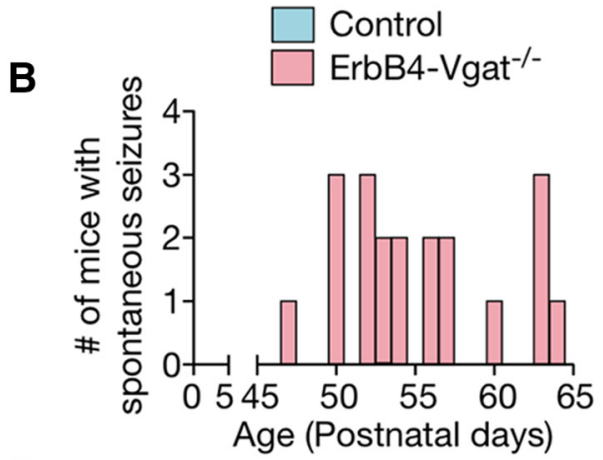

C

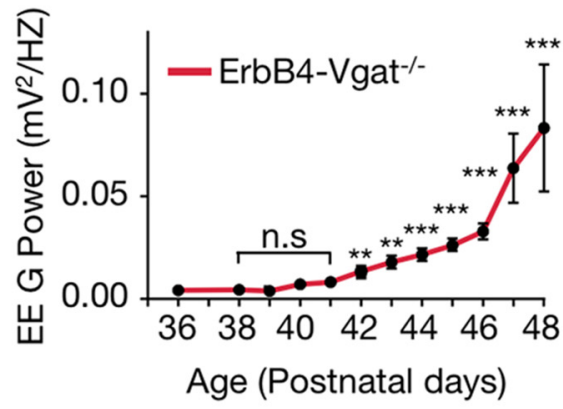

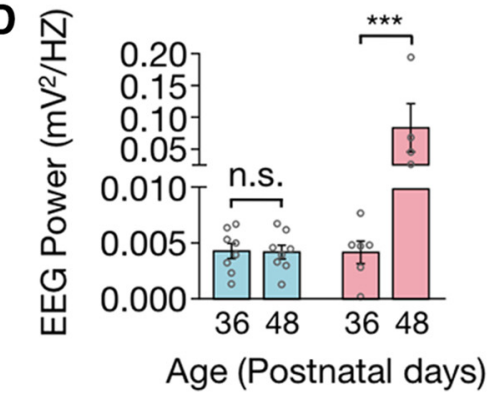

Figure 2. No electrographic seizure activities were seen before P45 in ErbB4-Vgat ${ }^{-1-}$ mice. A, Representative EEG traces of an ErbB4-Vgat ${ }^{-/-}$mouse. Traces indicated by red lines were zoomed out below. Abnormal spike-like activities were not observed until P42 and no electrographic seizure activities were observed until P46. B, Numbers of ErbB4-Vgat ${ }^{-1-}$ mice with first-onset spontaneous seizure $(n=20)$. C, Summarized EEG power $(0.5-40 \mathrm{~Hz})$ spectrum density. $D$, EEG power spectrum density of control and ErbB4-Vgat ${ }^{-1-}$ mice at P36 and P48. $n=6$ and 8 controls and ErbB4-Vgat ${ }^{-1-}$ mice, respectively. n.S., Not significant. Error bars indicate SEM. ${ }^{*} p<0.05 ; * * 0<0.01 ;{ }^{* * *} p<0.001$.

(Huang, 2014; Luhmann et al., 2015). To determine whether cortical neuronal populations were altered, cortical slices were stained with NeuN, a marker of neuronal nuclei (Mullen et al., 1992). As shown in Figure $3, A, B$, and $D$, the densities of NeuNlabeled neurons were similar between ErbB4-Vgat ${ }^{-1-}$ and control mice. This result indicates that Vgat mutation in ErbB4 ${ }^{+}$ interneurons at $\mathrm{P} 10$ has little effect on the neuronal population. In control mice, $\mathrm{PV}^{+}$interneurons were not present in L1, but were present in L2/3, L4, L5, and L6, with the highest population in L5 (Fig. 3E), in agreement with previous reports (Gonchar et al., 2007; Xu et al., 2010). Similar distribution pattern and number of $\mathrm{PV}^{+}$neurons were observed in ErbB4-Vgat ${ }^{-1-}$ mutant mice (Fig. 3E). Because Vgat is mutated in ErbB4 ${ }^{+}$interneurons, it would be important to determine whether the mutation alters their number and distribution in the cortex. As shown in Figure 3F, ErbB4 ${ }^{+}$ interneurons (i.e., labeled by tdTomato) were populated throughout the cortical layers L1-L6, with the number of ErbB4 ${ }^{+}$interneurons being highest in L2/3 and L5, in agreement with the previous study (Bean et al., 2014). The number and distribution of ErbB4 ${ }^{+}$interneurons in all cortical layers were similar between ErbB4-Vgat ${ }^{-1-}$ and control mice (Fig. 3F). These results suggest that Vgat knock-out at P10 does not alter the migration and lamination of $\mathrm{PV}^{+}$or ErbB4 ${ }^{+}$interneurons.
In L4 and L5 of the cortex, a majority of ErbB $4{ }^{+}$interneurons are $\mathrm{PV}^{+}(66.5 \pm 5.23 \%$ and $69.7 \pm 5.23 \%$ in L4 and L5, respectively), whereas, in L2/3, only $40.2 \pm 3.74 \%$ of ErbB4 ${ }^{+}$cells were $\mathrm{PV}^{+}$(Fig. 3G). This indicates that there are more ErbB4-only interneurons in superficial layers and more double positive $\left(\mathrm{PV}^{+} \mathrm{ErbB}^{+}\right)$interneurons in deep layers, in agreement with a previous report (Bean et al., 2014). Conversely, of $\mathrm{PV}^{+}$interneurons, $93 \%$ were positive for ErbB4 (i.e., recombined by Tam induction) at L2/3; the percentages of these double-positive neurons were reduced to $83 \%$ in $\mathrm{L} 5$ and $87 \%$ in L6 (Fig. $3 H$ ). This indicates that PV-only interneurons are sparse and mostly distributed in L5 and L6 (Fig. $\left.3 A^{\prime}-B^{\prime \prime}\right)$. Vgat mutation in ErbB4 ${ }^{+}$ interneurons seemed to have little effect on the number and distribution of ErbB4-only, $\mathrm{PV}^{+} \mathrm{ErbB}^{+}$, and PV-only interneurons in different cortical layers (Fig. $3 E-H$ ). These results demonstrate that Vgat knock-out at P10 in ErbB4 ${ }^{+}$interneurons did not alter the number of pyramidal neurons or interneurons in the cortex, providing an excellent model with which to determine whether and how GABA transmission regulates synapse development.

Fewer axo-somatic inhibitory synapses onto excitatory neurons $\mathrm{PV}^{+}$interneurons, accounting for $\sim 40-50 \%$ of total interneurons, have been studied extensively (Bartos et al., 2007; Cardin et 
A

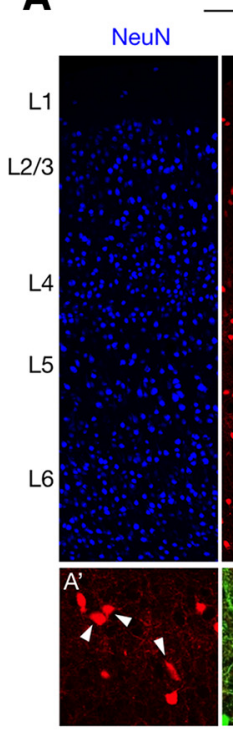

E

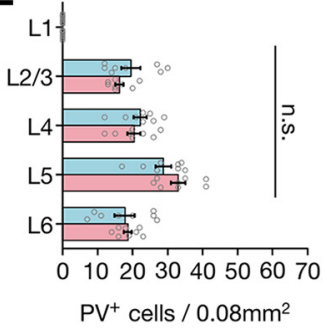

Control

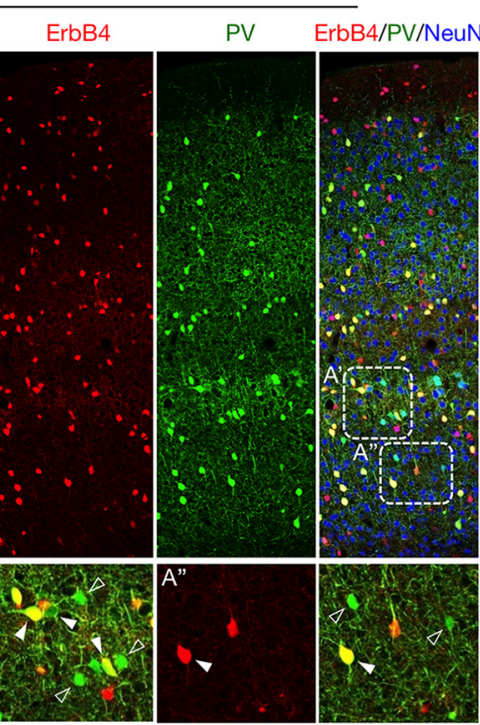

F

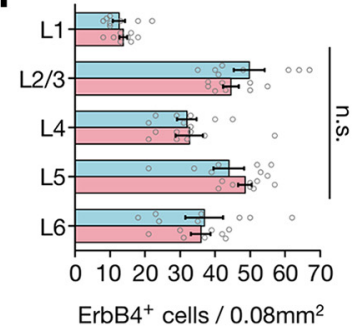

B

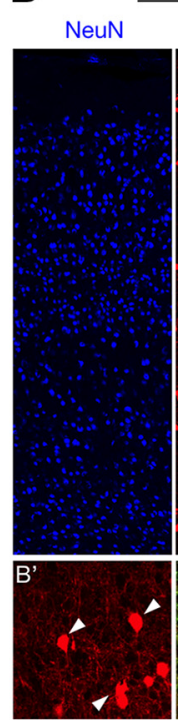

ErbB4-Vgat ${ }^{-1-}$

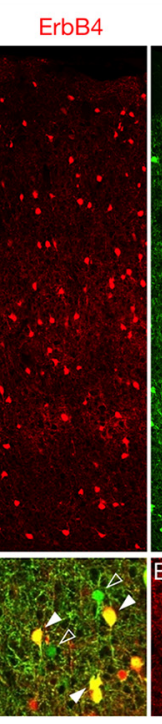

C

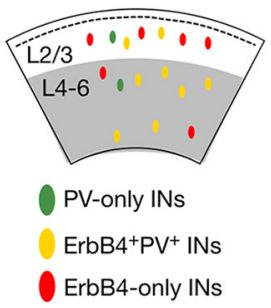

ErbB4/PV/NeuN

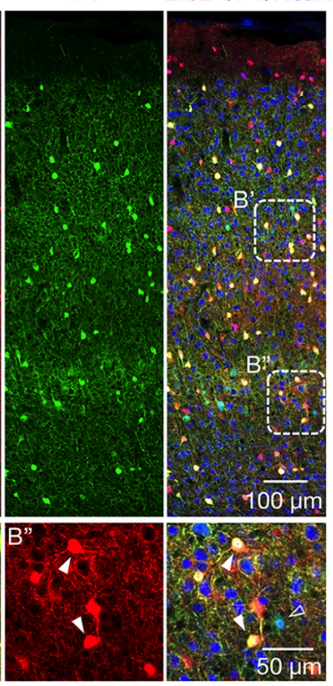

D

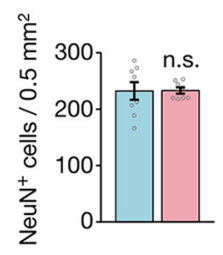

$\square$ Control

$\square$ ErbB4-Vgat ${ }^{-/-}$

G

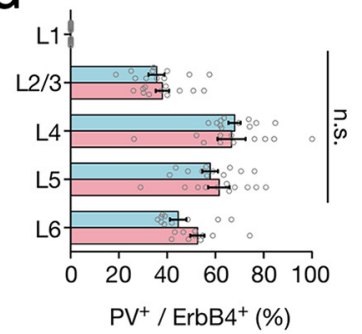

H

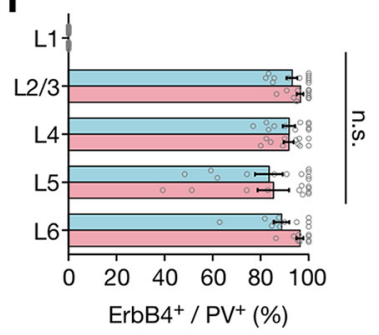

Figure 3. Normal laminar distribution of $\mathrm{PV}^{+}$and ErbB4 ${ }^{+}$interneurons in ErbB4-Vgat ${ }^{-1-}$ mice. $A, B$, Representative coronal sections showing genetically labeled ErbB4 ${ }^{+}$interneurons (red) and $\mathrm{PV}^{+}$interneurons (green), with NeuN (blue) staining as background in controls $(\boldsymbol{A})$ and ErbB4-Vgat ${ }^{-1-}(\boldsymbol{B})$ mice. Dotted rectangles are enlarged at the bottom to highlight ErbB4 ${ }^{-}, \mathrm{PV}-$ only interneurons (green, open arrowheads) and PV ${ }^{+}$ErbB4 ${ }^{+}$interneurons (yellow, closed arrowheads) in control $\left(\boldsymbol{A}^{\prime}, \boldsymbol{A}^{\prime \prime}\right)$ and ErbB4-Vgat ${ }^{-I-}\left(\boldsymbol{B}^{\prime}, \boldsymbol{B}^{\prime \prime}\right) . \boldsymbol{C}$, Distribution diagram of indicated interneurons in superficial and deep cortical layers. $\boldsymbol{D}$, Similar NeuN ${ }^{+}$cell density in control and ErbB4-Vgat ${ }^{-1-}$ mice $(n=9$ sections, 4 mice per group). $\boldsymbol{E}-\boldsymbol{H}$, Similar number and distribution of $\mathrm{PV}^{+}(\boldsymbol{E}), \mathrm{ErbB4}^{+}(\boldsymbol{F})$, percentage of $\mathrm{PV}^{+} / \mathrm{ErbB}^{+}(\boldsymbol{G})$, and percentage of ErbB4 ${ }^{+} / \mathrm{PV}^{+}(\boldsymbol{H})$ cells in different cortical layers $(n=9$ sections, 4 mice per group). INs, Interneurons; n.S., not significant. Error bars indicate SEM.

al., 2009; Sohal et al., 2009; Hu et al., 2014). Their dysfunction has been implicated in the pathophysiology of a wide variety of neurodevelopmental and neuropsychiatric disorders such as autism and schizophrenia (Lewis et al., 2012; Marin, 2012; Lewis, 2014). $\mathrm{PV}^{+}$basket cells typically form axo-somatic and axo-axonic synapses; an individual basket cell could target 200-1000 neurons in rat and $\sim 800$ neurons in mouse (Packer et al., 2011; Kubota, 2014). $\mathrm{PV}^{+}$chandelier cells synapse onto AISs to form axo-axonic synapses (Somogyi, 1977; Kawaguchi et al., 1997; Karube et al., 2004); a chandelier cell may innervate $35-50 \%$ of pyramidal neurons within its axon arbor range (Inan et al., 2013). However, the total number of the inhibitory synapses onto individual pyramidal neurons and inhibitory neurons remain unclear. Therefore, we first characterized the inhibitory synapses by $\mathrm{PV}^{+} \mathrm{ErbB}^{+}$, ErbB4-only, and PV-only interneurons in different cortical layers. $\mathrm{L} 1$ has no projection neurons and few if any $\mathrm{PV}^{+}$interneurons (Jiang et al., 2013; Fig. 3, $A, B$, and $E$ ). Interneurons in L1, most of which are positive for ErbB4 (Bean et al., 2014), project to interneurons in L2/3 and excitatory neurons in L5 (Jiang et al., 2013).

ErbB4 ${ }^{+}$terminals (visualized by tdTomato) appeared as boutons in the cortex (Fig. $4 A, C, E$ ), as observed for GABAergic presynaptic terminals (Inan et al., 2013; Taniguchi et al., 2013; S. X. Chen et al., 2015). A majority of ErbB4 ${ }^{+}$terminals $(\sim 97 \%)$ costained with GAD67, an isoform of GAD that has been used as a marker of axon terminals of GABAergic neurons (Huang et al., 2007; Ka- naani et al., 2010; Miceli et al., 2017; Fig. 4A,B). ErbB4 ${ }^{+}$terminals could also be stained with PV, which has been used to mark inhibitory synapses (Del Pino et al., 2013; Kobayashi et al., 2015; Ye et al., 2015; Fig. 4A,E). The percentage of ErbB4 versus GAD67 colocalization was not changed by Vgat mutation. To confirm that ErbB4 ${ }^{+}$boutons represent GABAergic synapse-forming terminals, we stained gephyrin, a tubulin-binding protein critical for GABA receptor clustering (Essrich et al., 1998). Gephyrin has been widely used as a postsynaptic marker of inhibitory synapses ( $\mathrm{Wu}$ et al., 2012). Somas of pyramidal neurons were visualized with the antibody against NeuN (blue, Alexa Fluor 647-labeled secondary antibody). ErbB4 ${ }^{+}$terminals were visualized by tdTomato that was expressed in ErbB4 ${ }^{+}$neurons. As shown in Figure $4 C$, a majority of ErbB4 ${ }^{+}$boutons were in contact or partially overlap with gephyrin-labeled punctae at the soma ( $86 \pm 2.5 \%$ and $84 \pm 2.6 \%$ in control and ErbB4-Vgat ${ }^{-1-}$ mice, respectively; Fig. $4 D$ ), indicating that most of these boutons were axonal terminals of inhibitory synapses onto projection neurons.

To quantify inhibitory synapses, image stacks were rendered in Vaa3D, a 3D visualization-assisted analysis tool (Peng et al., 2010 ), to generate $3 \mathrm{D}$ volumetric images that allows for interactive rotation. Individual presynaptic boutons in contact with the somas were marked and quantified using the 3D marker tool (Fig. $4 E, F)$. The $Z$-thickness of $3 \mathrm{D}$ volumetric images was adjusted or 
A

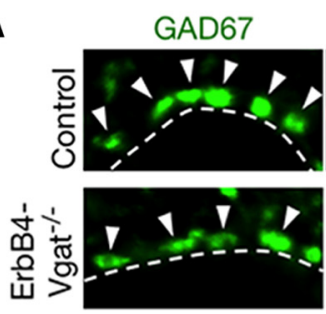

ErbB4
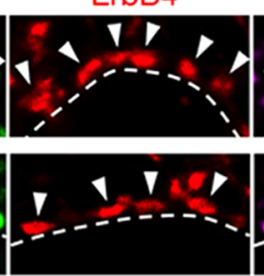

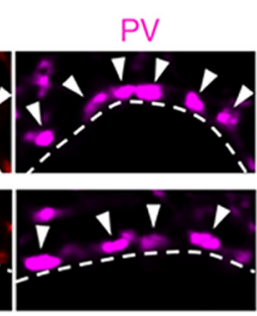

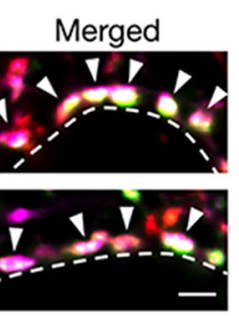

B

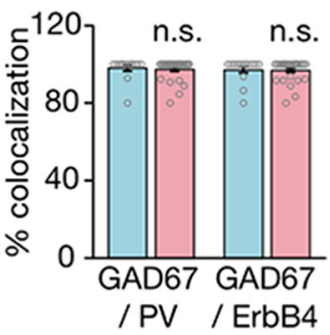

C

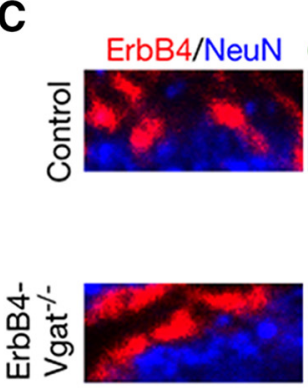

Gephyrin/ErbB4

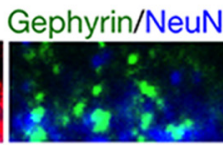

NeuN

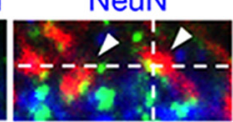

$\times$
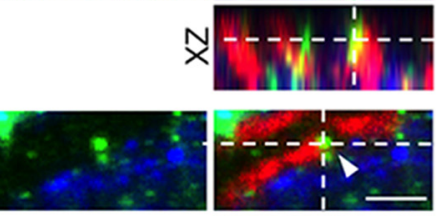

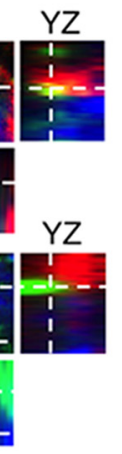

N
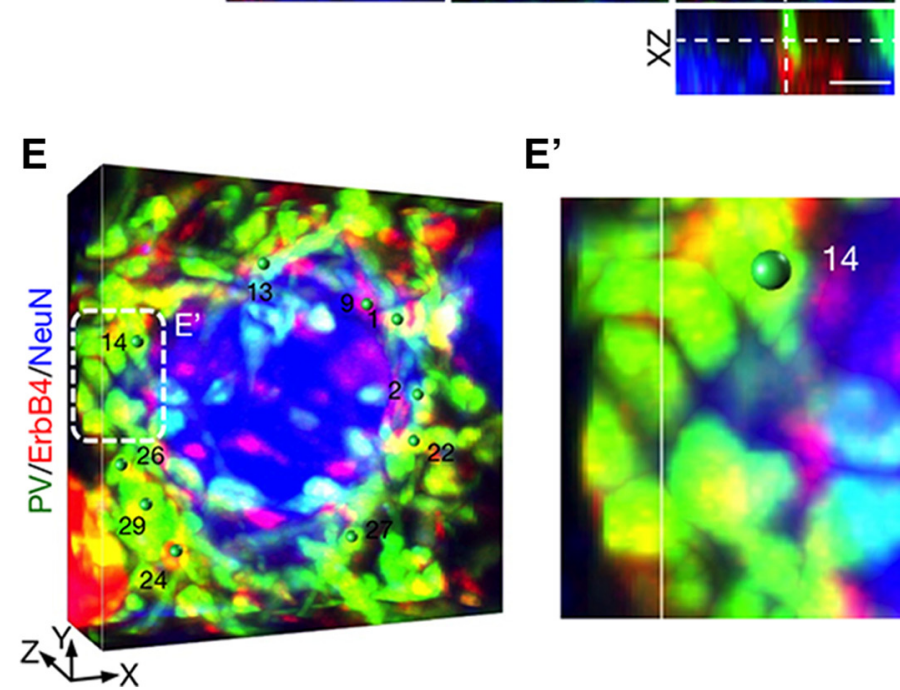

$E^{\prime}$

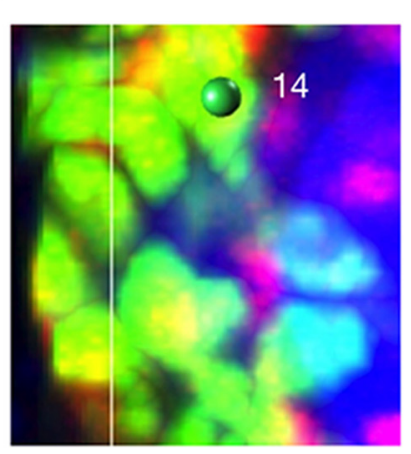

D
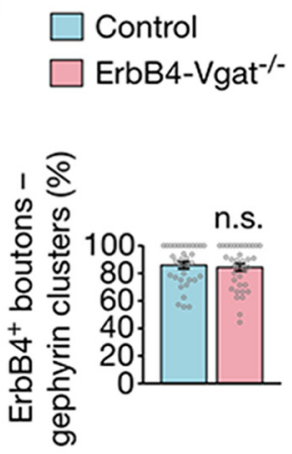

E $\longrightarrow \underset{\perp}{\longrightarrow}$
F

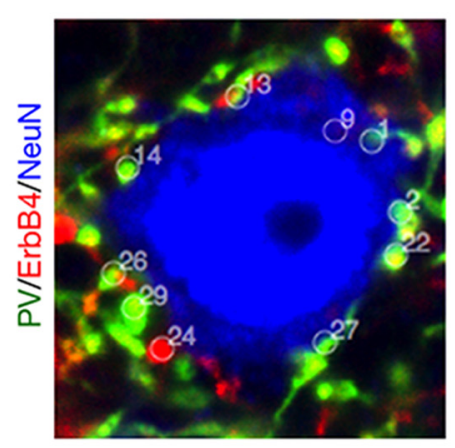

Figure 4. ErbB4 ${ }^{+}$and $\mathrm{PV}^{+}$presynaptic boutons as synapse-forming terminals. A, Cortical sections of control and ErbB4-Vgat ${ }^{-1-}$ mice were stained with the antibody against GAD67, which were visualized by the fluorescence-conjugated secondary antibody (green). Somas are outlined by dotted white lines. Arrowheads indicate $\mathrm{PV}^{+}$and ErbB4 ${ }^{+}$presynaptic boutons that were positive for GAD67. Scale bar, $2 \mu \mathrm{m}$. B, Percentage of GAD67/PV and GAD67/ErbB4 boutons per soma (control, $n=14$; ErbB4-Vgat ${ }^{-1-}, n=28$ somas, 3 mice per group). C, ErbB4 ${ }^{+}$boutons in contact or partial overlap with the inhibitory postsynaptic marker gephyrin. Cortical sections of control and ErbB4-Vgat ${ }^{-1-}$ mice were stained with the antibody against gephyrin, which were visualized by the fluorescence-conjugated secondary antibody (green). Somas of pyramidal neurons were labeled by NeuN (blue). Arrowheads indicate ErbB4 ${ }^{+}$boutons that are in contact or partial overlap with gephyrin clusters. Scale bar, $2 \mu \mathrm{m}$. D. Percentage of ErbB4 ${ }^{+}$boutons and gephyrin clusters/total ErbB4 ${ }^{+}$boutons per soma (control, $n=34 ;$ ErbB4-Vgat ${ }^{-1-}, n=36$ somas, 3 mice per group). $\boldsymbol{E}-\boldsymbol{F}, 3 \mathrm{D}$ quantification of $\mathrm{PV}^{+}$and/or ErbB4 ${ }^{+}$axo-somatic synapses. Shown are representative images generated by Vaa3D as described in the Materials and Methods. Volumetric images $\left(\boldsymbol{E}, \boldsymbol{E}^{\prime}\right)$ show boutons marked with green spheres, which correspond to white circles in single-plane images like the one shown in $\boldsymbol{F}$. $\boldsymbol{E}^{\prime}$, Higher-magnification image of the dotted area in E. Scale bar, $5 \mu$ m. n.s., Not significant. Error bars indicate SEM.

zoomed in to ensure that only marked boutons in contact with somas or AISs were accounted for and quantified only once.

In control mice, a typical projection neuron soma receives $65.3 \pm 4.18$ in L2/3, $54.5 \pm 4.26$ in L4, $90.5 \pm 4.35$ in L5, and $39.9 \pm 2.54$ in $\mathrm{L} \mathrm{PV}^{+}$ErbB4${ }^{+}$axo-somatic inhibitory synapses per soma (Fig. 5B). $\mathrm{PV}^{+}$ErbB4 ${ }^{+}$axo-somatic inputs onto pyramidal neurons were highest at L5 compared with each of the other layers $\left(F_{(3,64)}=28.34, p<0.0001\right.$, post hoc power $\left.=1\right)$. ErbB4-only axo-somatic inputs per soma were higher in L2/3 and L6 (10.9 \pm 0.98 and $8.9 \pm 1.20$, respectively, but lowest in $\operatorname{L5}\left(F_{(3,63)}=8.138\right.$, $p=0.0001$, post hoc power $=1$; Fig. $5 C)$. In contrast, $\mathrm{PV}$-only interneurons formed far fewer inhibitory synapses $(\sim 0-2$ per soma) throughout cortical layers (Fig. 5D).

In ErbB4-Vgat ${ }^{-1-}$ mice, $\mathrm{PV}^{+}$ErbB4 ${ }^{+}$axo-somatic synapses were reduced in both superficial (L2/3) and deep cortical layers
(L4-L6), compared with control $\left(\mathrm{L} 2 / 3, t_{(31)}=3.387, p=0.002\right.$, post hoc power $=0.92 ; \mathrm{L} 4, t_{(28)}=2.542, p=0.016$, post hoc power $=0.64 ; \mathrm{L} 5, t_{(45)}=2.996, p=0.004$, post hoc power $=0.83$ and L6, $t_{(31)}=2.865, p=0.007$, post hoc power $=0.79$; Fig. $5 B$ ). Conversely, the numbers of ErbB4-only synapses were not changed in ErbB4-Vgat ${ }^{-1-}$ mice (Fig. 5C). PV-only synapses were not altered by Vgat mutation in ErbB4 ${ }^{+}$neurons (Fig. $5 D$ ), which is not unexpected because Vgat was not mutated in PV-only interneurons. To determine whether the morphological changes alter neurotransmission, we measured mIPSCs of pyramidal neurons by whole-cell patch-clamp recordings. mIPSC frequencies were decreased in both L2/3 and L5/6 pyramidal neurons of ErbB4Vgat $^{-/-}$mice compared with controls (in control and ErbB4Vgat $^{-/-}$, respectively: $7.9 \pm 0.49$ vs $3.3 \pm 0.35 \mathrm{~Hz}$ in L2/3, $t_{(12)}=$ $7.159, p<0.0001$, post hoc power $=0.99$; and $10.4 \pm 0.99$ vs $5.4 \pm$ 

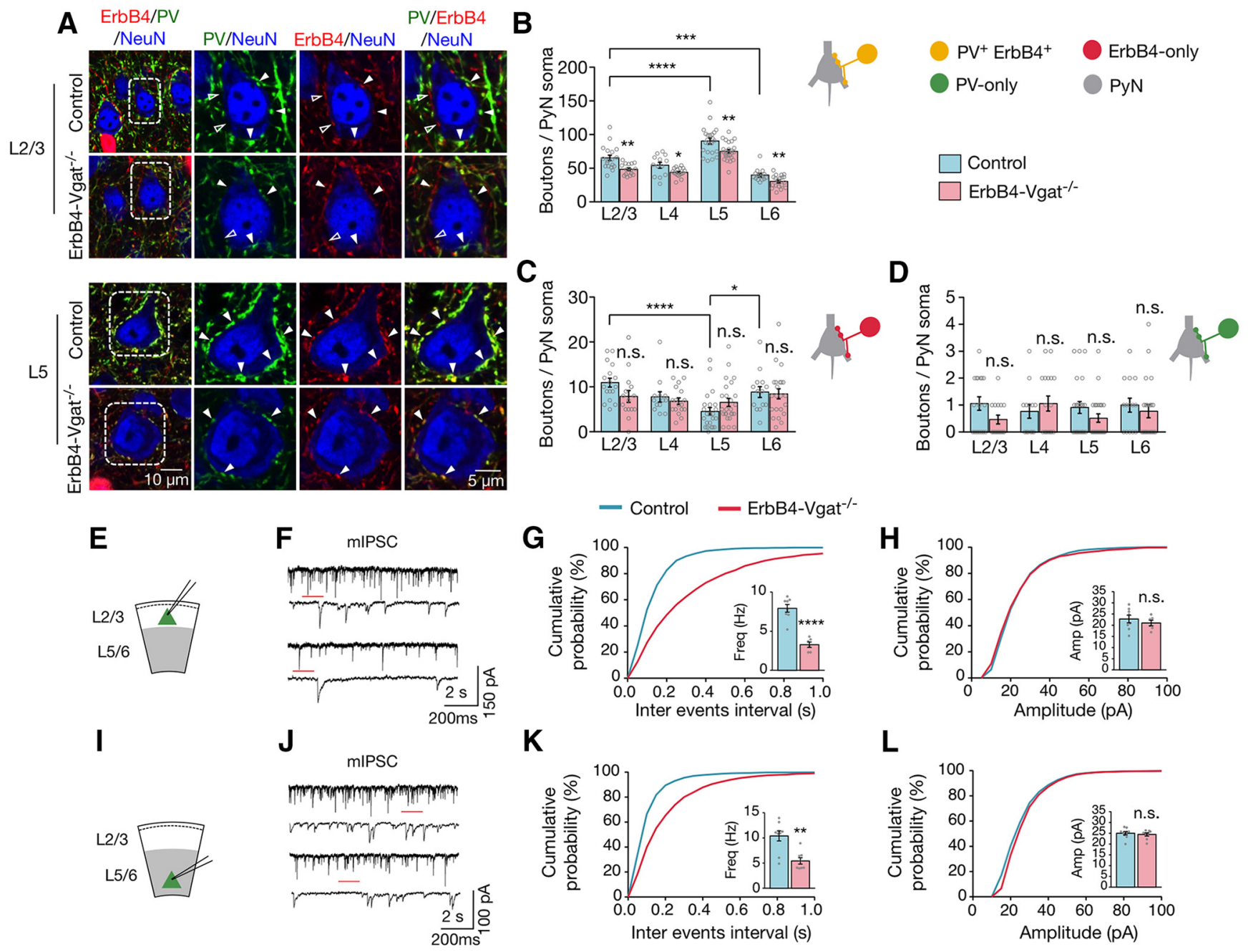

$$
\text { - Control - ErbB4-Vgat }{ }^{-/-}
$$
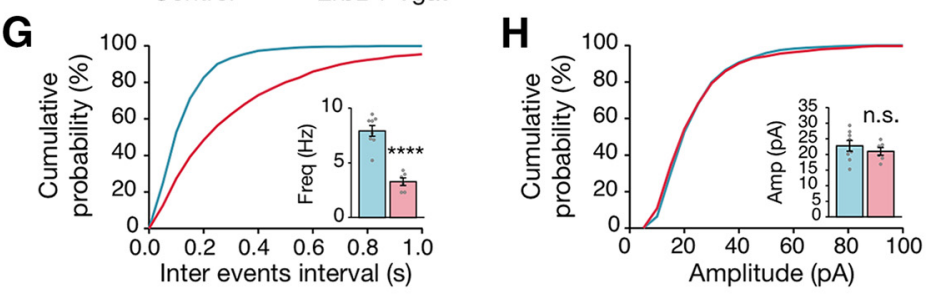

K
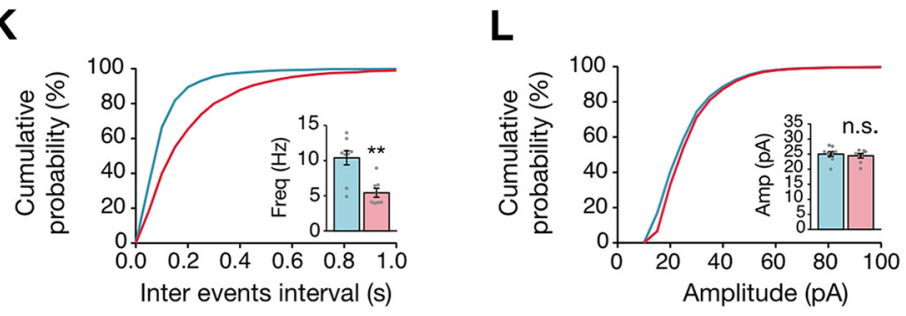

Figure 5. Decreased axo-somatic inhibitory synapses by PV ${ }^{+}$ErbB4 ${ }^{+}$interneurons onto excitatory neurons. A, Representative Z-plane images of axo-somatic synapses onto pyramidal neurons. Cortical sections of control and ErbB4-Vgat ${ }^{-1-}$ mice were stained with antibodies against PV and NeuN. Shown are L2/3 and L5 somas in which ErbB4 ${ }^{+}$boutons are labeled in red (tdTomato), PV boutons in green, and NeuN in blue. Open arrowheads indicate boutons that are either PV-only or ErbB4-only and closed arrowheads indicate PV ${ }^{+}$ErbB4 ${ }^{+}$boutons. Higher magnification images of dotted areas are shown on the right. $\boldsymbol{B}-\mathbf{D}$, Quantitative analysis of axo-somatic synapses that are PV ${ }^{+}$ErbB4 ${ }^{+}(\boldsymbol{B})$, ErbB4-only $(\boldsymbol{C})$, and PV-only (D). Control, $n=18,13$, 23 , and 14 somas in L2/3, L4, L5, and L6, respectively, 4 mice; ErbB4-Vgat ${ }^{-1-}, n=15,17,24$, and 19 somas in L $2 / 3, L 4, L 5$, and L6, respectively, 4 mice. $E$, I, Schematics of whole-cell patch-clamp recordings of $L 2 / 3(\boldsymbol{E})$ and $L 5 / 6(\boldsymbol{I})$ pyramidal neurons in cortical slices. $\boldsymbol{F}, J$, Representative traces of mIPSCs from $L 2 / 3(\boldsymbol{F})$ and $L 5 / 6(\boldsymbol{J})$ pyramidal neurons in control and ErbB4-Vgat ${ }^{-/}{ }^{-}$mice. Traces indicated by red lines are shown magnified below. $\boldsymbol{G}, \boldsymbol{H}$, Reduced mIPSC frequency $(\boldsymbol{G})$ and no change in mIPSC amplitude $(\boldsymbol{H})$ in L2/3 pyramidal neurons of ErbB4-Vgat ${ }^{-1-}$ mice compared with controls. Control, $n=8$ cells; ErbB4-Vgat ${ }^{-1-}, n=6$ cells, 3 mice per group. $\boldsymbol{K}, \boldsymbol{L}$, Reduced mIPSC frequency $(\boldsymbol{K})$ and no change in mIPSC amplitude $(\boldsymbol{L})$ in L5/6 pyramidal neurons of ErbB4-Vgat ${ }^{-/-}$ mice compared with controls. Control, $n=9$ cells, 3 mice; ErbB4-Vgat ${ }^{-1-}, n=8$ cells, 3 mice. Shown are cumulative probability plots for interevent intervals and amplitudes of mIPSCs. Insets, bar graphs for mIPSC frequency (Freq) and amplitude (Amp). n.s., Not significant. Error bars indicate SEM. ${ }^{*} p<0.05 ;{ }^{* *} p<0.01$; ${ }^{* * *} p<0.001$; ${ }^{* * *} p<0.0001$.

$0.63 \mathrm{~Hz}$ in $\mathrm{L} 5, t_{(15)}=4.071, p=0.001$, post hoc power $=0.97$; Fig. $5 G, K)$. In contrast, no change in mIPSC amplitudes was observed (Fig. $5 H, L$ ). Together, these results indicate that GABA transmission from ErbB4 ${ }^{+}$interneurons is necessary for the development of axo-somatic synapses in the cortex in a layerspecific manner.

\section{Fewer axo-axonic inhibitory synapses onto excitatory neurons}

In addition to axo-somatic synapses, the output of pyramidal neurons is controlled by axo-axonic synapses; that is, those onto axon initial segments (Somogyi, 1977; Somogyi et al., 1982). To determine whether GABA transmission regulates these synapses, the AISs were visualized with the antibody against ankyrin-G (cyan), an AIS marker (Jenkins et al., 2001). To show that ErbB4 ${ }^{+}$axonal boutons are GABAergic synapses, we costained brain sections with an antibody against gephyrin and ankyrin-G. As shown in
Figure 6, $A$ and $B$, a majority of ErbB $4^{+}$boutons (82.6 $\pm 3.46 \%$ in controls and $79.6 \pm 3.71 \%$ in ErbB4-Vgat ${ }^{-1-}$ ) were in contact or partially overlapped with gephyrin-labeled punctae at the AISs, indicating that most of these boutons were axonal terminals of inhibitory synapses onto the AISs.

To quantify the total number of inhibitory synapses on to AISs, 3D volumetric images were generated and synaptic boutons onto AISs were quantified as described in the Materials and Methods and Figure 4, $E$ and $F$. As shown in Figure 6, $C$ and $D$, in control mice, axo-axonic synapses per AIS by $\mathrm{PV}^{+} \mathrm{ErbB}^{+}{ }^{+}$interneurons were similar from L2/3 to L5 (18.4 \pm 0.65 in L2/3, $19.1 \pm 1.11$ in L4, $18.1 \pm 1.25$ in L5), but lower in L6, $14.5 \pm 1.30$ synapses per AIS $\left(F_{(3,84)}=3.235, p=0.02\right.$, post hoc power $\left.=1\right)$. Axo-axonic inputs per AIS from ErbB4-only interneurons were highest in L6 and L2/3 (2.4 \pm 0.52 and $1.6 \pm 0.35$, respectively), followed by L4 ( $1.1 \pm 0.32)$ and L5 $\left(0.4 \pm 0.19 ; F_{(3,83)}=4.24, p=\right.$ 0.007 , post hoc power $=0.99$; Fig. $6 E$ ). PV-only axo-axonic syn- 

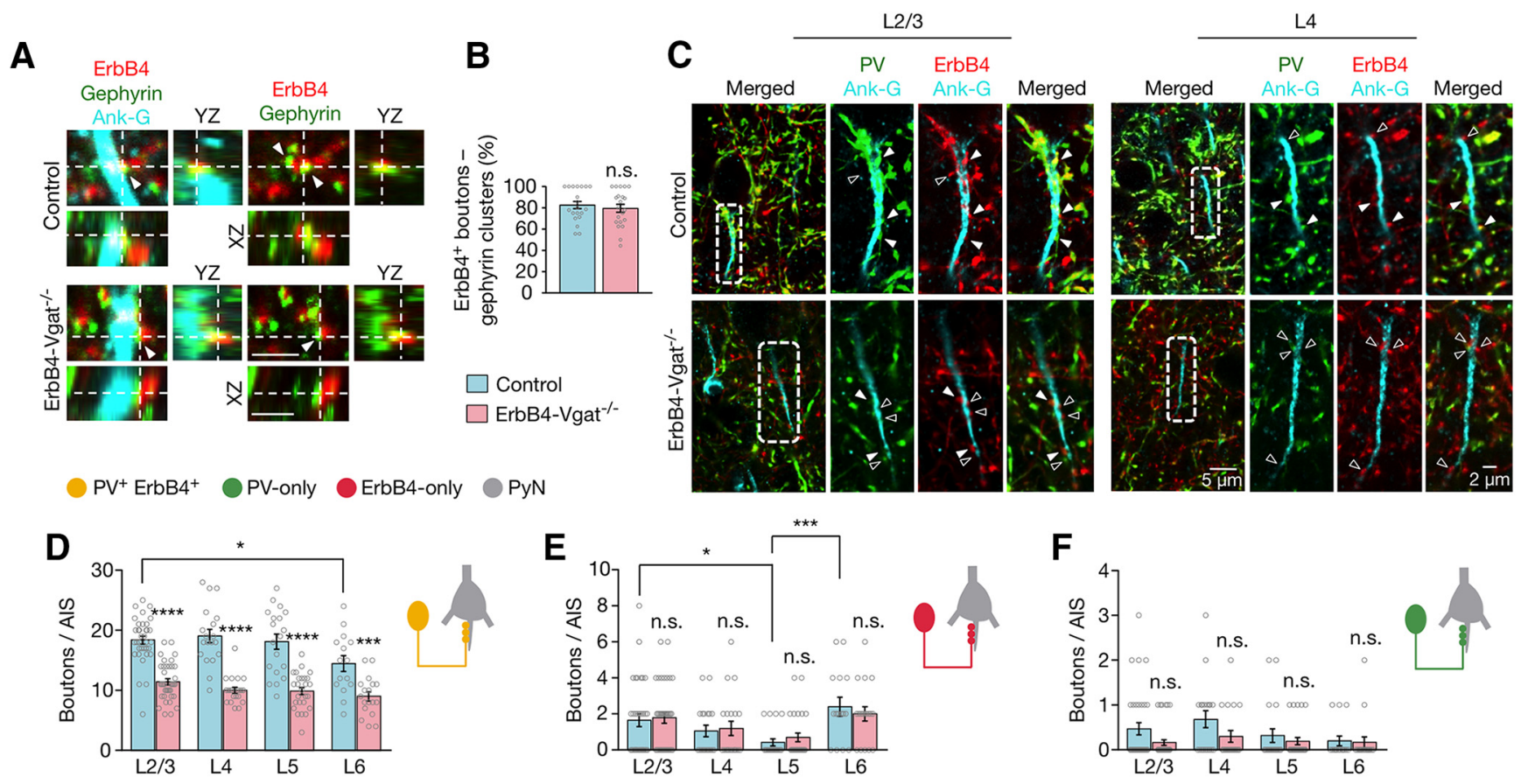

Figure 6. Decreased axo-axonic inhibitory synapses onto pyramidal neuron AISs. A, ErbB4 ${ }^{+}$boutons are in contact or partial overlap with the inhibitory postsynaptic marker gephyrin. Cortical sections of control and ErbB4-Vgat ${ }^{-1-}$ mice were stained with the antibody against gephyrin, which were visualized by the fluorescence-conjugated secondary antibody (green). AlSs were labeled by ankyrin-G (cyan). Arrowheads indicate ErbB4 ${ }^{+}$boutons that are in contact or partial overlap with gephyrin clusters. Scale bar, $2 \mu \mathrm{m} . \boldsymbol{B}$, Percentage of ErbB4 ${ }^{+}$boutons and gephyrin clusters/total ErbB4 ${ }^{+}$boutons per AIS (control, $n=19$ AISs; ErbB4-Vgat ${ }^{-1-}, n=21$ AISs, 3 mice per group). C, RepresentativeZ-plane images of axo-axonic synapses onto pyramidal neuron AISs. Cortical sections of control and ErbB4-Vgat ${ }^{-1-}$ mice were stained with antibodies against PV and ankyrin-G. Shown are L2/3 and L4 AISs in which ErbB4 ${ }^{+}$boutons are labeled in red (tdTomato), PV boutons in green, and ankyrin-G in cyan. Open arrowheads indicate boutons that are either PV-only or ErbB4-only and closed arrowheads indicate PV ${ }^{+}$ErbB4 ${ }^{+}$boutons. Higher-magnification images of dotted areas are shown on the right. $\boldsymbol{D}-\boldsymbol{F}$, Quantitative analysis of axo-axonic synapses that are PV ${ }^{+}$ErbB4 ${ }^{+}(\boldsymbol{D})$, ErbB4-only $(\boldsymbol{E})$, and PV-only $(\boldsymbol{F})$. Control, $n=35,19,19$, and 15 AlSs in L2/3, L4, L5, and L6, respectively, 4 mice; ErbB4-Vgat ${ }^{-1-}, n=37,20,26$, and 18 AISs in L2/3, L4, L5, and L6, respectively, 4 mice. Ank-G, Ankyrin-G; n.s., not significant. Error bars indicate SEM. ${ }^{*} p<0.05$.

apses were far fewer, at $0-3$ per AIS, and did not differ between all cortical layers (Fig. 6F).

Vgat mutation significantly reduced double-positive AIS synapses in $\mathrm{L} 2 / 3$ to $\mathrm{L} 6$ by 38\% in L2/3, 48\% in L4, 45\% in L5, and $38 \%$ in L6 $\left(_{(70)}=8.439, t_{(37)}=7.531, t_{(43)}=6.451\right.$ and $t_{(31)}=$ 3.768 , respectively; $p<0.0001, \mathrm{~L} 2 / 3-\mathrm{L} 5$ and $p=0.0007$, L6; post hoc power $>0.95$, L2/3-L6; Fig. 6D), indicating dependence on GABA signaling. Vgat mutation appeared to have little effect on ErbB4-only and PV-only AIS synapses in all layers (Fig. 6E,F). These results suggest that Vgat mutation (induced at P10) has critical effects on developing axo-axonic synapses.

\section{No effect of Vgat mutation on axo-somatic inhibitory synapses onto interneurons}

We next studied the effect of Vgat mutation on inhibitory synapses onto inhibitory neurons. To this end, cortical sections were stained with antibodies against synaptotagmin-2 (SYT2), a synaptic vesicle protein present at $\mathrm{PV}^{+}$synaptic boutons (Sommeijer et al., 2012). We costained for $\mathrm{GABA}_{\mathrm{A}} \mathrm{R}-\alpha 1$, a major subunit of $\mathrm{GABA}_{\mathrm{A}} \mathrm{R}$ that has been used as a postsynaptic marker of axosomatic synapses (Kasugai et al., 2010; Panzanelli et al., 2011). Approximately $97 \%$ of SYT $2{ }^{+}$boutons were in contact or partially overlap with $\mathrm{GABA}_{\mathrm{A}} \mathrm{R}-\alpha 1$, indicating that SYT2 ${ }^{+}$boutons represent inhibitory synapses in both genotypes (Fig. $7 A, B$ ). Therefore, Coimmunostaining of SYT2 and PV enabled visualization and differentiated $\mathrm{PV}^{+}$inhibitory synapses onto inhibitory interneurons. As described above, control mice express tdTomato in ErbB $4{ }^{+}$interneurons. First, we analyzed three types of inhibitory synapses: $\mathrm{PV}^{+}$or SYT2 ${ }^{+}$terminals onto entire interneuron somas of $\mathrm{PV}^{+}$ErbB4$^{+}$and ErbB4-only and PV-only interneurons.
To quantify the total number of inhibitory synapses on interneurons, we captured confocal $Z$-projection images of entire somas in $0.4 \mu \mathrm{m}$ steps. 3D volumetric images were generated and individual boutons were quantified as described in Figure $4, E$ and $F$. Representative images of a single $Z$-plane are shown for each type of interneurons (Fig. 7C,D). In control mice, PV-only interneurons receive more $\mathrm{SYT}_{2}{ }^{+}$inhibitory axo-somatic synapses in deep cortical layers L5 and L6 compared with superficial layers $\mathrm{L} 2 / 3$ (25.6 \pm 2.24 in $\mathrm{L} 2 / 3$ vs $36.8 \pm 2.56$ in $\mathrm{L} 5$ and $36.0 \pm 3.05$ in L6; $F_{(3,36)}=3.06, p=0.04$, post hoc power $=1$; Fig. $7 G$ ). Axosomatic SYT2 ${ }^{+}$inhibitory synapses onto ErbB4-only interneurons were relatively fewer in L2/3 (17.6 \pm 2.77 per soma) and their distribution was highest in $\mathrm{L} 5\left(30.91 \pm 3.03\right.$ per soma; $F_{(3,41)}=$ 5.046, $p=0.005$, post hoc power $=1$; Fig. $7 F$ ). Conversely, the numbers of axo-somatic inhibitory synapses onto $\mathrm{PV}^{+} \mathrm{ErbB}^{+}{ }^{+}$interneurons were similar in number in all cortical layers, ranging from $\sim 33$ to 48 per soma (Fig. 7E). PV-only and ErbB4-only interneurons in $\mathrm{L} 2 / 3$ receive fewer SYT2 ${ }^{+}$inhibitory inputs $(\sim 25$ and $\sim 17$ synapses, respectively) compared with $\mathrm{PV}^{+} \mathrm{ErbB} 4{ }^{+}$interneurons ( $\sim 32$ synapses) in L2/3 (Fig. 7E-G). Vgat mutation in ErbB4 ${ }^{+}$ interneurons appeared to have little effect on SYT2 ${ }^{+}$axo-somatic inhibitory synapses onto interneurons (Fig. $7 E-G$ ).

ErbB4-only neurons may synapse onto $\mathrm{PV}^{+}$interneurons and such synapses could be visualized by ErbB $4^{+}$boutons onto anti-PV antibody-labeled somas. In control mice, the numbers of ErbB4-only inhibitory synapses onto PV-only interneurons were similar (Fig. $7 H$ ). The numbers of these synapses were not affected in ErbB4-Vgat ${ }^{-1-}$ mice (Fig. $7 H$ ). PV-only inhibitory synapses onto ErbB4-only interneurons soma with no overlapping anti-SYT2 immunofluorescence can be distinguished visually. 
A
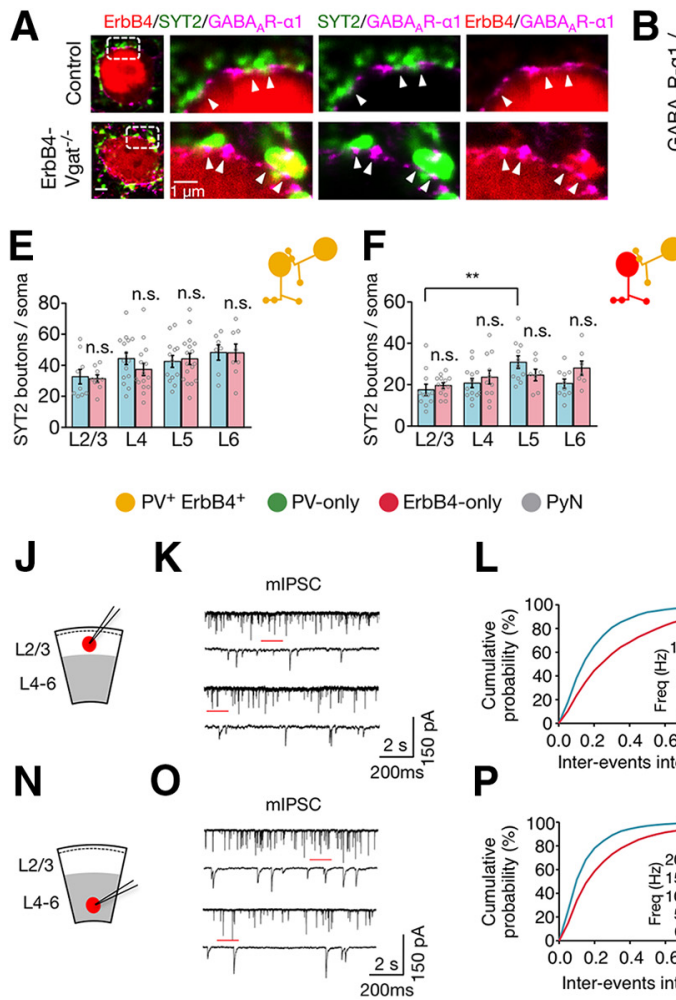

B
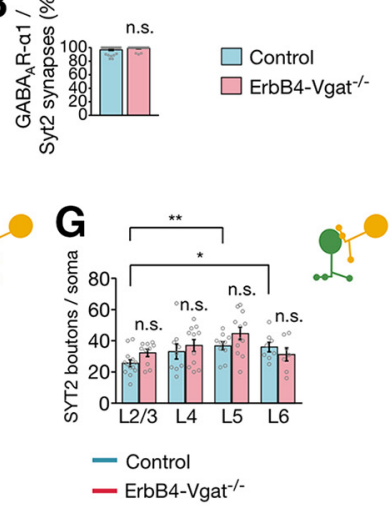

L

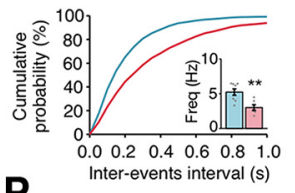

$\mathbf{P}$

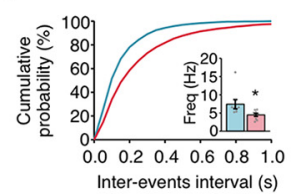

M
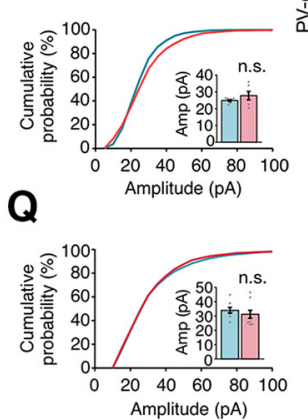

$\square$ Control $\square$ ErbB4-Vgat $^{-1-}$
C

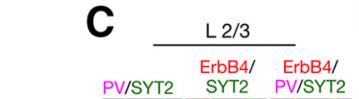

D
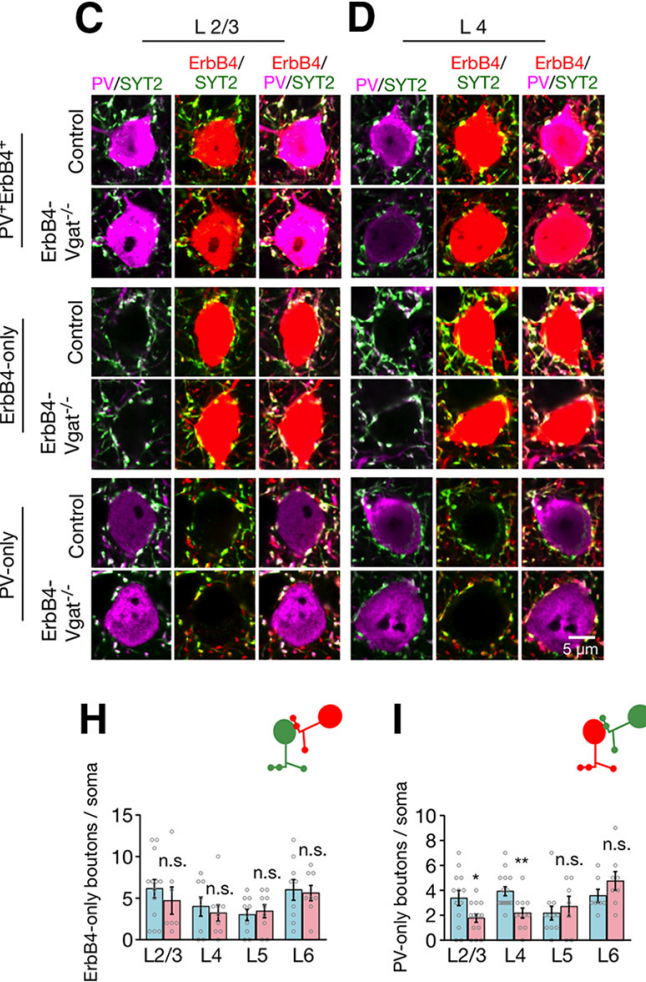

Figure 7. Similar SYT2 ${ }^{+}$inhibitory synapses onto inhibitory neurons, but reduced SYT2 ${ }^{-}$/PV-only synapses onto ErbB4-only interneurons. $\boldsymbol{A}$, SYT2 punctae in contact or partial overlap with $G_{A B A} R \alpha 1$ punctae. Cortical sections were stained with antibodies against SYT2 and $G A B A_{A} R \alpha 1$, which were visualized by fluorescence-conjugated secondary antibodies (green and magenta, respectively). Genetically labeled ErbB4 ${ }^{+}$interneuron somas are represented in red (tdTomato). Shown on the right are high-magnification images of the dotted rectangles area. Arrowheads indicate SYT2 boutons in contact or partial overlap with GABA $R \alpha 1$ punctae representing inhibitory synapses. $B$, Percentage of GABA $A_{A} R 1 / S Y T 2$ punctae per soma (control, $n=28$ somas; ErbB4-Vgat ${ }^{-1-}, n=25$ somas, 3 mice per group). C, D, Representative Z-plane images of axo-somatic synapses onto interneurons. Cortical sections of control and ErbB4-Vgat ${ }^{-1-}$ mice were stained with antibodies against PV and SYT2. Shown are L2/3 $(\boldsymbol{C})$ and $L 4(\boldsymbol{D})$ interneurons in which ErbB4 ${ }^{+}$boutons are labeled in red (tdTomato), PV boutons in magenta, and SYT2 in green. $\boldsymbol{E}-\boldsymbol{G}$, Quantitative analysis of SYT2 ${ }^{+}$inhibitory axo-somatic synapses onto PV ${ }^{+}$ErbB4 ${ }^{+}$interneurons $(\boldsymbol{E})$, ErbB4-only interneurons $(\boldsymbol{F})$, and PV-only interneurons $(\boldsymbol{G}) . \boldsymbol{H}$, No change in SYT2 $^{-}$, ErbB4-only inhibitory synapses onto PV-only interneurons. $I$, Reduced SYT2 ${ }^{-}$, PV-only inhibitory synapses onto ErbB4-only interneurons. PV ${ }^{+}$ErbB4 ${ }^{+}$interneurons: control, $n=9,15,13$, and 7 cells in L2/3, L4, L5, and L6, respectively, 4 mice; ErbB4-Vgat ${ }^{-1-}, n=9,15,17$, and 8 cells in L 2/3, L4, L5, and L6, respectively, 4 mice. ErbB4-only interneurons: control, $n=13,15,11$, and 10 cells in L2/3, L4, L5, and L6, respectively, 4 mice; ErbB4-Vgat ${ }^{-1-}, n=14,11,7$, and 7 cells in L2/3, L4, L5, and L6, respectively, 4 mice. PV-only interneurons: control, $n=13,9,10$, and 9 cells in $\mathrm{L} 2 / 3, \mathrm{~L} 4, \mathrm{~L} 5$, and L6, respectively, 4 mice; ErbB4-Vgat ${ }^{-I-}, n=10,11,12$, and 8 cells in L2/3, L4, L5, and L6, respectively, 4 mice. J, $N$, Schematics of whole-cell patch-clamp recordings of $\mathrm{L} 2 / 3$ ( $J$ ) and L4-L6 (N) ErbB4 ${ }^{+}$interneurons in cortical slices. $\boldsymbol{K}, \mathbf{0}$, Representative traces of mIPSCs from L2/3 $(\boldsymbol{K})$ and L4-L6 (0) ErbB4 ${ }^{+}$interneurons in control and ErbB4-Vgat ${ }^{-/-}$mice. Traces indicated by red lines are shown magnified below. $\boldsymbol{L}, \boldsymbol{M}$, Reduced $\mathrm{mIPSC}$ frequency $(\boldsymbol{L})$ and no change in $\mathrm{mIPSC}$ amplitude $(\boldsymbol{M})$ in L2/3 ErbB4 ${ }^{+}$interneurons of ErbB4-Vgat ${ }^{-I-}$ mice compared with controls. Control, $n=8$ cells, 3 mice; ErbB4-Vgat ${ }^{-1-}, n=6$ cells, 3 mice. $\boldsymbol{P}, \boldsymbol{Q}$, Reduced mIPSC frequency $(\boldsymbol{P})$ and no change in mIPSC amplitude $(\mathbf{Q})$ in $\mathrm{L} 4-\mathrm{L} 6$ ErbB4 ${ }^{+}$interneurons of ErbB4-Vgat ${ }^{-1-}$ mice compared with controls. Control, $n=8$ cells, 3 mice; ErbB4-Vgat ${ }^{-1-}, n=9$ cells, 3 mice. Shown are cumulative probability plots for interevent intervals and amplitudes of mIPSCS. Insets, Bar graphs for mIPSC frequency and amplitude. Freq, frequency, Amp, amplitude. n.s., Not significant. Error bars indicate SEM. ${ }^{*} p<0.05 ;{ }^{* *} p<0.01$.

These $\mathrm{SYT}^{-}, \mathrm{PV}^{+}$terminals onto ErbB4-only interneurons account for $3.4 \pm 0.60$ in $\mathrm{L} 2 / 3,3.9 \pm 0.36$ in L4, $2.2 \pm 0.55$ in L5, and $3.6 \pm 0.53$ in L6 per soma (Fig. 7I). The numbers of these synapses in superficial and deep cortical layers were similar in control mice, whereas they were decreased in L $2 / 3(3.4 \pm 0.60 \mathrm{vs}$ $1.8 \pm 0.33, t_{(25)}=2.359, p=0.03$, post hoc power $\left.=0.61\right)$ and $\mathrm{L} 4$ $\left(3.9 \pm 0.36\right.$ vs $2.2 \pm 0.40, t_{(24)}=3.238, p=0.004$, post hoc power $=0.87)$ in ErbB4-Vgat ${ }^{-1-}$ mice (Fig. 7I).

To determine whether Vgat mutation alters the transmission at inhibitory synapses onto inhibitory neurons, we recorded mIPSCs of ErbB4 ${ }^{+}$interneurons in whole-cell patch-clamp configuration. ErbB $4^{+}$interneurons were visualized by tdTomato. mIPSC frequencies were reduced in ErbB4 ${ }^{+}$interneurons in both superficial and deep cortical layers in ErbB4-Vgat ${ }^{-1-}$ mice compared with control mice (L2/3: $t_{(12)}=3.500, p=0.004$, post hoc power $=0.91$ and L4-L6: $t_{(15)}=2.301, p=0.03$, post hoc power $=0.60$; Fig. $7 L, P$ ). The implication of these results is highlighted in the Discussion.

\section{Increased excitatory inputs onto $\mathrm{PV}^{+} \mathrm{ErbB} 4{ }^{+}$cells in deep cortical layers}

To determine whether excitatory inputs to interneurons are affected by GABA transmission, cortical sections were stained for VGLUT-1, a presynaptic excitatory synaptic protein of local pyramidal neurons (Kaneko et al., 2002). Coimmunostaining for PSD-95, a postsynaptic marker of excitatory synapses (Chen et al., 2011) indicated that VGLUT-1 punctae are in contact or partially overlap with those of PSD-95 in ErbB4 ${ }^{+}$interneurons (95.7 \pm 1.6 and $98.4 \pm 0.9 \%$ in control and ErbB4-Vgat ${ }^{-1-}$ mice, respectively; Fig. $8 A, B$ ), confirming VGLUT-1 as a marker of excitatory synapses (Fazzari et al., 2010). In control mice, $\mathrm{PV}^{+} \mathrm{ErbB}^{+}$ interneurons were associated with $0.61 \pm 0.03 / \mu \mathrm{m}$ VGLUT-1 punctae in L2/3. The density of these synapses was decreased in L5 and L6 $\left(0.49 \pm 0.02\right.$ and $0.46 \pm 0.03 / \mu \mathrm{m}$, respectively; $F_{(3,31)}=$ $3.002, p=0.04$; Fig. $8 E$ ). In contrast, ErbB4-only interneurons in both superficial and deep cortical layers received a similar number of excitatory inputs (Fig. $8 F$ ). The Vgat mutation increased 


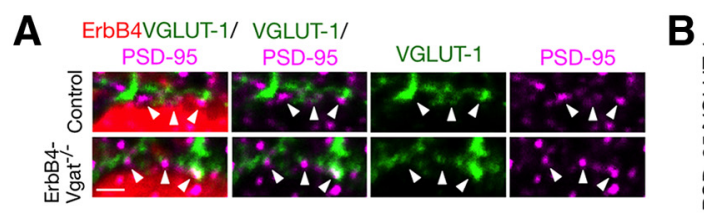

C
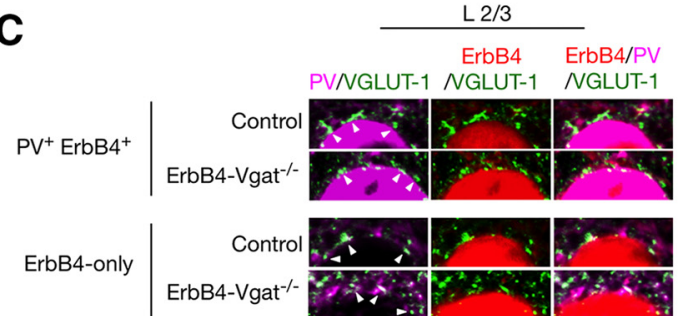

PV-only

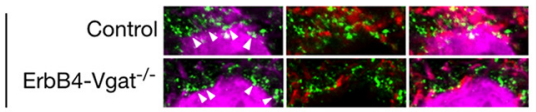

$\mathrm{PV}^{+} \mathrm{ErbB}_{4}^{+}$

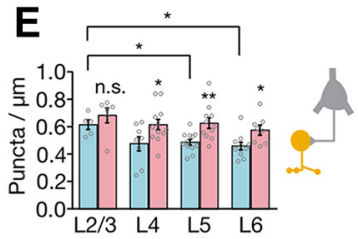

F

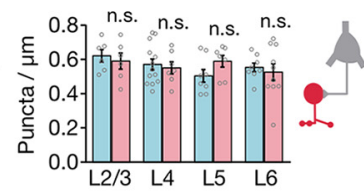

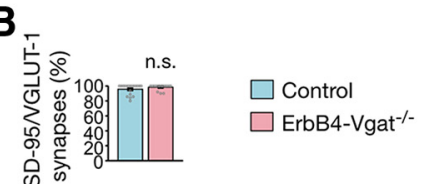
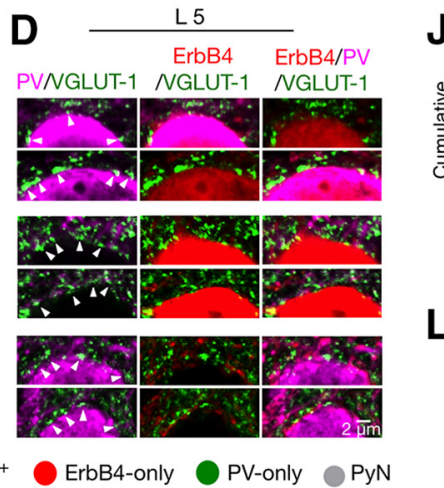

G

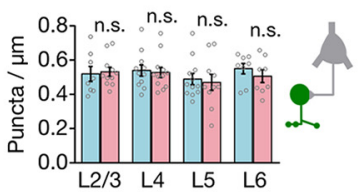

H

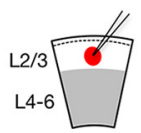

I

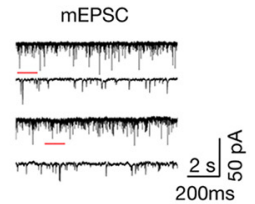

J

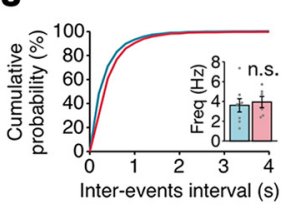

K

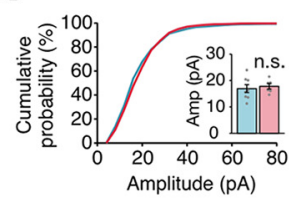

L

- Control - ErbB4-Vgat ${ }^{-1}$

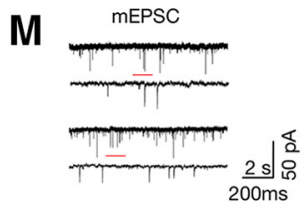

N

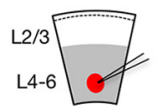

0

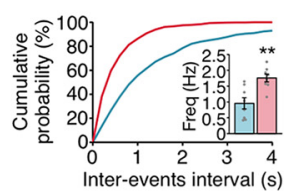

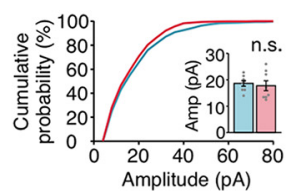

Figure 8. Increased excitatory inputs onto PV ${ }^{+}$ErbB4 ${ }^{+}$interneurons in deep layers. A, VGLUT-1 punctae in contact or partial overlap with PSD-95 punctae. Cortical sections were stained with antibodies against VGLUT-1 and PSD-95, which were visualized by fluorescence-conjugated secondary antibodies (green and magenta, respectively). Genetically labeled ErbB4 ${ }^{+}$interneuron somas were represented in red (tdTomato). Arrowheads indicate Vglut-1 punctae in contact or partial overlap with PSD-95 punctae, representing excitatory synapses. $\boldsymbol{B}$, Percentage of Vglut-1/PSD-95 punctae per soma (control, $n=19$ somas; ErbB4-Vgat ${ }^{-1-}, n=17$ somas, 3 mice per group). $\boldsymbol{C}, \boldsymbol{D}$, Representative images of excitatory axo-somatic synapses onto interneurons. Cortical sections of control and ErbB4-Vgat ${ }^{-1-}$ mice were stained with antibodies against PV and VGLUT-1. Shown are L2/3 (C) and L5 (D) interneurons, where ErbB4 ${ }^{+}$somas were labeled in red (tdTomato), VGLUT-1 punctae in green, and PV in magenta. $\boldsymbol{E}-\mathbf{G}$, Quantitative analysis of excitatory synapses onto PV ${ }^{+}$ErbB4 ${ }^{+}$interneurons $(\boldsymbol{E})$, ErbB4-only $(\boldsymbol{F})$, and PV-only $(\boldsymbol{G} ; n=6$ sections per mice; $5-7$ somas per cortical layer per section, 3 mice per group). $\boldsymbol{H}, \boldsymbol{L}$, Schematics of whole-cell patch-clamp recordings of $L 2 / 3(\boldsymbol{H})$ and $L 4-\mathrm{L} 6(\boldsymbol{L})$ ErbB4 ${ }^{+}$interneurons in cortical slices. $\boldsymbol{I}, \boldsymbol{M}, \mathrm{Representative}$ traces of mEPSCS from L2/3 $(\boldsymbol{I})$ and $\mathrm{L} 4-\mathrm{L} 6(\boldsymbol{M})$ ErbB4 ${ }^{+}$interneurons in control and ErbB4-Vgat ${ }^{-/-}$mice. Traces indicated by red lines are shown magnified below. $J, \boldsymbol{K}$, No change in mEPSC frequency $(\boldsymbol{J})$ and amplitude $(\boldsymbol{K})$ in L2/3 ErbB4 ${ }^{+}$interneurons of ErbB4-Vgat ${ }^{-1-}$ mice compared with controls. Control, $n=8$ cells, 3 mice; ErbB4-Vgat ${ }^{-1-}, n=6$ cells, 3 mice. $\boldsymbol{N}, \mathbf{0}$, Increased $\mathrm{mEPSC}$ frequency $(\boldsymbol{N})$ and no change in mEPSC amplitude $(\boldsymbol{O})$ in $\mathrm{L} 4-\mathrm{L} 6$ ErbB4 ${ }^{+}$interneurons of ErbB4-Vgat ${ }^{-\prime-}$ mice compared with controls. Control, $n=8$ cells, 3 mice; ErbB4-Vgat ${ }^{-l-}, n=$ 8 cells, 3 mice. Shown are cumulative probability plots for interevent intervals and amplitudes of mEPSCs. Insets, Bar graphs for mEPSC frequency and amplitude. n.s., Not significant. Error bars indicate SEM. ${ }^{*} p<0.05 ;{ }^{* *} p<0.01$.

Table 1. Intrinsic properties of $\mathrm{L} 2 / 3$ and $\mathrm{L} 5 / 6$ pyramidal and ErbB4 ${ }^{+}$interneurons

\begin{tabular}{|c|c|c|c|c|c|c|c|c|}
\hline \multirow[b]{3}{*}{ Properties } & \multicolumn{4}{|l|}{$\mathrm{L} 2 / 3$} & \multicolumn{4}{|l|}{$\mathrm{L} 5 / 6$} \\
\hline & \multicolumn{2}{|l|}{ Pyramidal } & \multicolumn{2}{|c|}{ ErbB4 ${ }^{+}$interneuron } & \multicolumn{2}{|l|}{ Pyramidal } & \multicolumn{2}{|c|}{ ErbB4 ${ }^{+}$interneuron } \\
\hline & Control & ErbB4-Vgat $^{-1-}$ & Control & ErbB4-Vgat ${ }^{-1-}$ & Control & ErbB4-Vgat $^{-1-}$ & Control & ErbB4-Vgat $^{-1-}$ \\
\hline$V_{\mathrm{rmp}}[\mathrm{mV}]$ & $-69.5 \pm 19.7$ & $-71.0 \pm 1.2$ & $-68.9 \pm 13.6$ & $-67 \pm 16.1$ & $-72.3 \pm 1.4$ & $-65.6 \pm 1.6^{* * *}$ & $-70.6 \pm 1.7$ & $-63.6 \pm 2.1^{* * *}$ \\
\hline
\end{tabular}

Data are shown as means \pm SEM.

$R_{\text {in }}$ Input resistance; $V_{\text {rmp, }}$ resting membrane potential.

${ }^{* * *} p<0.001 ; n=9$ neurons, 3 mice per genotype.

the number of excitatory inputs to $\mathrm{PV}^{+} \mathrm{ErbB} 4^{+}$interneurons in L4-L6 (by 29\% in L4, 28\% in L5 and 25\% in L6; $t_{(18)}=2.218, t_{(21)}=$ $3.276, t_{(16)}=2.542 ; p=0.04,0.004,0.02$ and post hoc power $=$ $0.60,0.87$, and 0.70 , respectively; Fig. $8 E$ ), but had little effect on excitatory inputs onto $\mathrm{L} 2 / 3 \mathrm{PV}^{+}$ErbB4 ${ }^{+}$interneurons or to ErbB4only and PV-only interneurons (Fig. $8 E-G$ ).

To study the effect of Vgat mutation on excitatory neurotransmission onto ErbB4 ${ }^{+}$interneurons, we performed whole-cell patchclamp recordings of $\mathrm{mEPSC}$ in the presence of TTX to block action potentials. mEPSC frequency was increased in deep layer ErbB4 $^{+}$interneurons in ErbB4-Vgat ${ }^{-/-}$mice compared with control $\left(1.8 \pm 0.12\right.$ vs $0.96 \pm 0.18 \mathrm{~Hz}$, respectively, $t_{(14)}=3.736$, $p=0.002$, post hoc power $=0.93$; Fig. $8 N$ ), consistent with our morphological observations (Fig. 8E). mEPSC amplitudes in both superficial and deep cortical layers were similar between controls and ErbB4-Vgat ${ }^{-1-}$ mice (Fig. $8 \mathrm{~K}, \mathrm{O}$ ). Vgat mutation had no effect on input resistance but increased the resting membrane potentials (RMP) of ErbB $4^{+}$neurons in deep layers (Table 1). Consistent with this, action potential (AP) F-I curves indicate more spikes in ErbB4-Vgat ${ }^{-1-}$ mice compared with control mice (F-I curves; Fig. 9J-L). We did not observe significant changes in AP waveforms (Fig. 9J-L). This result suggests increased excitability of ErbB $4{ }^{+}$interneurons in the absence of Vgat.

To determine whether the effect of Vgat mutation is cell autonomous or non-cell autonomous, we injected Erbb4 ${ }^{\mathrm{CreER}} ; V_{g a t}{ }^{\mathrm{f} / \mathrm{fl}} ; A i 9$ 

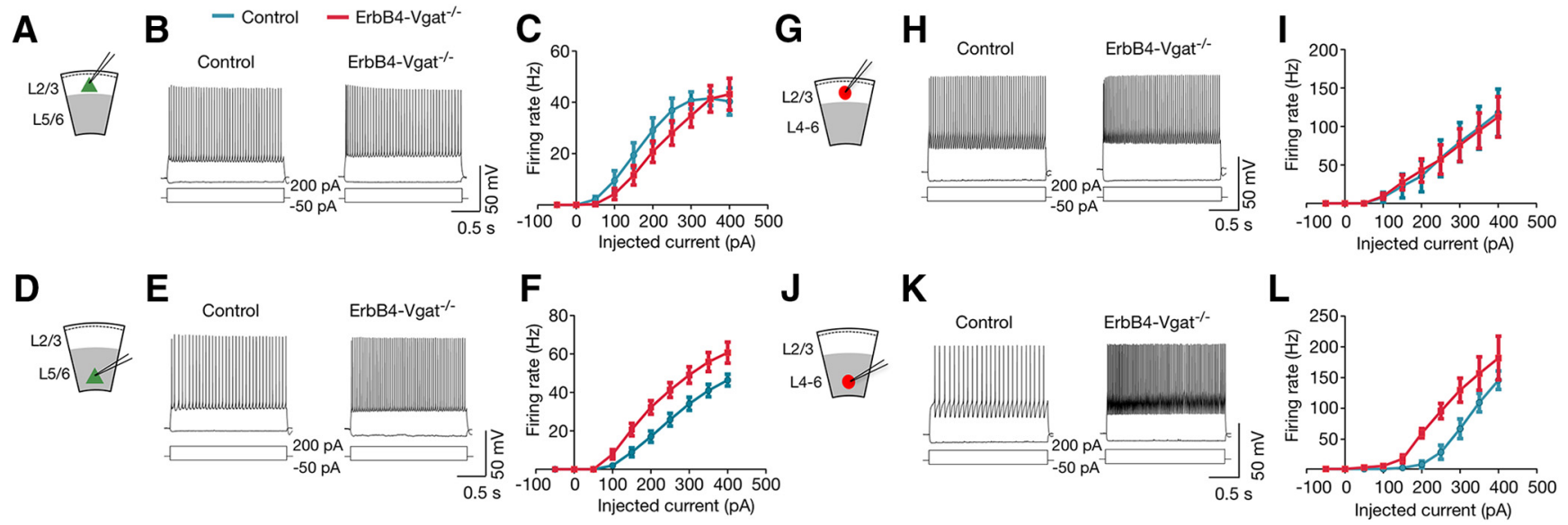

Figure 9. Increased excitability of pyramidal neurons and ErbB4 ${ }^{+}$interneurons in deep cortical layers of ErbB4-Vgat ${ }^{-1-}$ mice. $A, D, S$ Shematics of whole-cell patch-clamp recordings of $L 2 / 3$ ( $A$ ) and $L 5 / 6(\boldsymbol{D})$ pyramidal neurons in cortical slices. $\boldsymbol{B}, \boldsymbol{E}$, Representative traces of action potentials for $2 \mathrm{~s}$ step current injection ( -50 to $200 \mathrm{pA})$ in $L 2 / 3(\boldsymbol{B})$ and $L 5 / 6(\boldsymbol{E})$ pyramidal neurons in control and ErbB4-Vgat ${ }^{-I-}$ mice. $C, F$, Left shift of firing $F-I$ curves) in L5/6 pyramidal neurons, but not those in L2/3 in ErbB4-Vgat ${ }^{-I-}$ mice. L2/3: $n=10$ cells, 3 mice per genotype. L5/6: $n=10$ cells, 3 mice per genotype. $\mathbf{G}, \boldsymbol{J}$, Schematics of whole-cell patch-clamp recordings of $L 2 / 3(\boldsymbol{G})$ and $L 4-L 6(J)$ ErbB4 ${ }^{+}$interneurons in cortical slices. $\boldsymbol{H}, \boldsymbol{K}$, Representative traces of action potentials for $2 \mathrm{~s}$ step-current injection $(-50$ to $200 \mathrm{pA})$ in $\mathrm{L} 2 / 3(\boldsymbol{H})$ and $\mathrm{L} 4-\mathrm{L} 6(\boldsymbol{K})$ ErbB4 ${ }^{+}$interneurons in control and ErbB4-Vgat ${ }^{-/-}$mice. $\boldsymbol{I}, \boldsymbol{L}$, No change in average firing frequency versus current relationships ( $F-I$ curves) in $\mathrm{L} 2 / 3(\boldsymbol{I})$ and an increased in excitability (left shift in $F-I$ curve) in $\mathrm{L} 4-\mathrm{L} 6(\boldsymbol{L})$ ErbB4 ${ }^{+}$interneurons of ErbB4-Vgat ${ }^{-I}{ }^{-}$mice compared with controls. $\mathrm{L} 2 / 3: n=10$ cells, 3 mice per genotype. L5/6: $n=10$ cells, 3 mice per genotype. n.S., Not significant. Error bars indicate SEM.

mice (P10) with Tam at a single low dose (Fig. 10A). This led to sparse recombination of Vgat mutation in ErbB4 ${ }^{+}$interneurons (Fig. 10B). We determined the effect of Vgat mutation on excitatory synapses (labeled by anti-VGLUT-1) onto $\mathrm{PV}^{+}$interneurons. Because Vgat mutation in ErbB4 ${ }^{+}$interneurons had no effect on excitatory synapses in L2/3 (Fig. $8 E$ ), we thus focused on those in $\mathrm{L} 4$ where $92 \%$ of $\mathrm{PV}^{+}$cells are ErbB ${ }^{+}$(Fig. $3 \mathrm{H}$ ). As shown in Figure 10, $C$ and $D$, the excitatory synapses onto $\mathrm{PV}^{+}$ interneurons were not altered by Vgat mutation in ErbB ${ }^{+}$cells. These results suggest that the effect on excitatory synapses onto interneurons may be non-cell autonomous; that is, secondary to Vgat deletion.

Increased spines of pyramidal neurons in Vgat mutant mice We next studied whether Vgat is required for the development of pyramidal neurons. Erbb4 ${ }^{\mathrm{CreER}}$ and $E r b b 4^{\mathrm{CreER}} ; \mathrm{Vgat}{ }^{\mathrm{f} / \mathrm{fl}}$ mice were crossed with Thy1-GFP-S mice in which pyramidal neurons were sparsely labeled with GFP under the Thyl promoter (Feng et al., 2000). As shown in Figure $11 C$, apical dendritic lengths of L5 pyramidal neurons were similar between controls and ErbB4Vgat $^{-l-}$ mice $(2010 \pm 91.3$ and $2200 \pm 87.1 \mu \mathrm{m}$ per neuron, respectively, $p=0.66)$. Basal dendritic lengths were also similar (Fig. $11 C ; 1352 \pm 96.87$ and $1408 \pm 82.48 \mu \mathrm{m}$ per neuron respectively, $p=0.66)$. In addition, the numbers of primary $\left(1^{\circ}\right)$, secondary $\left(2^{\circ}\right)$, and tertiary $\left(3^{\circ}\right)$ dendritic branches were not affected in ErbB4-Vgat ${ }^{-1-}$ mice (Fig. $11 D ; 5.33 \pm 0.43$ and $6.43 \pm 0.311^{\circ}$ branches per neuron, respectively, and $8.43 \pm 0.72$ and $8.07 \pm 0.722^{\circ}$ and $3^{\circ}$ branches per neuron, respectively, $p=$ 0.05 and $p=0.72$, respectively). Sholl analysis revealed that the dendritic complexities of these neurons were also similar (Fig. $11 B)$. Similar negative results were observed for pyramidal neurons in superficial layers (data not shown). In particular, dendritic branches of $\mathrm{L} 2 / 3$ pyramidal neurons were similar between control and ErbB4-Vgat ${ }^{-1-}$ mice $\left(6.4 \pm 0.3\right.$ and $6.7 \pm 0.41^{\circ}$ branches per neuron; $8.1 \pm 0.9$ and $7.0 \pm 0.92^{\circ}$ and $3^{\circ}$ branches per neurons in control and ErbB4-Vgat ${ }^{-1-}$ mice, respectively; $n=8$ and 9 neurons in control and ErbB4-Vgat ${ }^{-1-}$ mice respectively). The Vgat mutation had no effect on the length of apical and basal dendrites of $\mathrm{L} 2 / 3$ pyramidal neurons ( $1450 \pm 80.0$ and
$1300 \pm 120.6$ for apical dendritic length; $1210 \pm 110.5$ and $1340 \pm 75.3$ for basal dendritic length in control and ErbB4Vgat $^{-1-}$ mice, respectively; $n=8$ and 9 neurons in control and ErbB4-Vgat ${ }^{-1-}$ mice respectively). Together, these results showed that Vgat of ErbB4 ${ }^{+}$interneurons is not necessary for dendrite development of cortical pyramidal neurons.

Next, we investigated the effects of Vgat deletion from ErbB $4{ }^{+}$interneurons on dendritic spines in L2/3 and L5 pyramidal neurons. There was an increase in apical spine density of L5 pyramidal neurons in ErbB4-Vgat ${ }^{-1-}$ mice compared with control mice $\left(11.1 \pm 0.49\right.$ spines $/ 10 \mu \mathrm{m}$ in ErbB4-Vgat ${ }^{-1-}$ and $8.77 \pm 0.39$ spines $/ 10 \mu \mathrm{m}$ in control mice, $t_{(109)}=3.679, p=$ 0.0004 , post hoc power $=0.98$; Fig. $12 \mathrm{~K})$. This appeared to be due to an increase in mushroom and stubby spines (Fig. 12M). There was no change in total basal dendritic spines of L5 pyramidal neurons in ErbB4-Vgat ${ }^{-1-}$ mice (Fig. 12L), although an increase in stubby spines and a decrease in filopodia were observed (Fig. 12N). There was no significant difference in the density of total apical and basal dendritic spines of L2/3 pyramidal neurons in ErbB4-Vgat ${ }^{-1-}$ mice compared with controls (Fig. $12 A-C$ ), although an increase in stubby spines was observed (Fig. 12D).

Whole-cell patch-clamp recordings of pyramidal neurons revealed increased mEPSC frequency in L5/6, but not in L2/3, in ErbB4-Vgat ${ }^{-1-}$ mice compared with control $\left(t_{(16)}=4.871\right.$, $p=0.0002$, post hoc power $=0.99$; Fig. $12 \mathrm{H}, \mathrm{Q})$. These observations suggest that Vgat of ErbB4 ${ }^{+}$interneurons may play a role in the pruning of dendritic spines during postnatal development or this may be a secondary effect of the decreased network inhibition. The RMP of pyramidal neurons in deep layers but not superficial layers was increased $(-72.3 \pm 1.4$ $\mathrm{mV}$ in control and $-65.6 \pm \mathrm{mV}$ in ErbB4-Vgat ${ }^{-1-}$ mice; Table 1). This was associated with an increase in APs in response to injected currents (Fig. 9D-F). No change in AP waveforms and input resistance was observed (Fig. 9D-F, Table 1). Together, these results revealed a cellular mechanism for spine density increase; that is, by increased neuronal activity of deep cortical pyramidal neurons. 
A

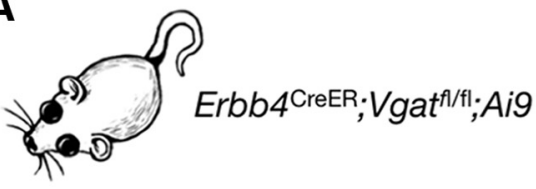

Postnatal day

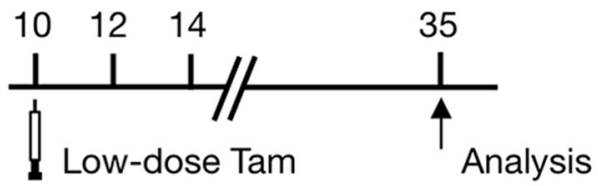

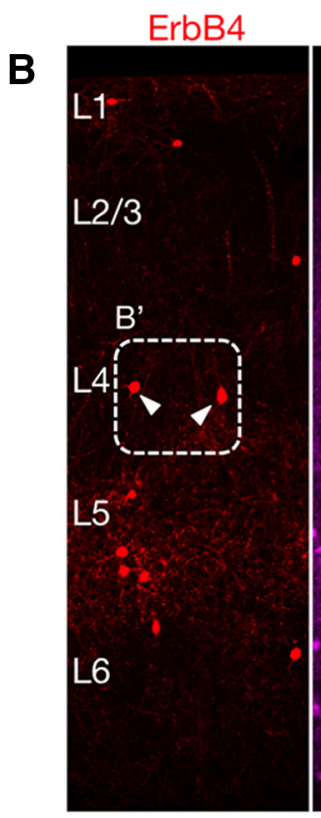
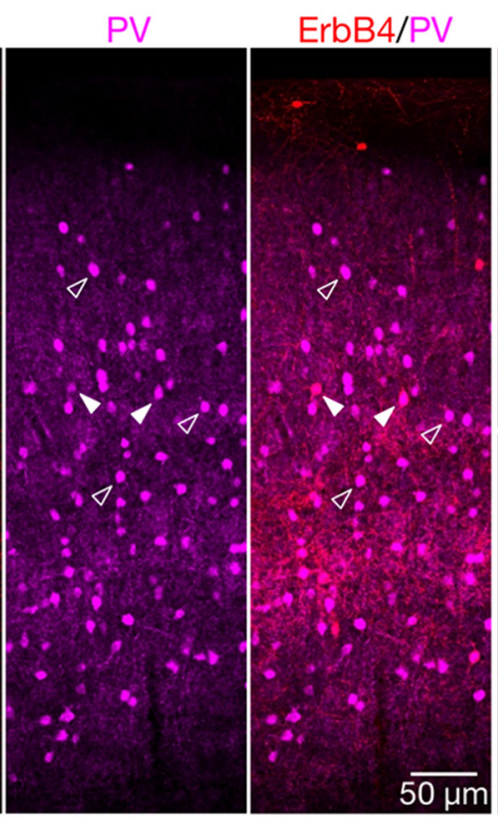

$\mathrm{PV}^{+} \mathrm{ErbB}^{+}$cells $-\mathrm{Tam}$

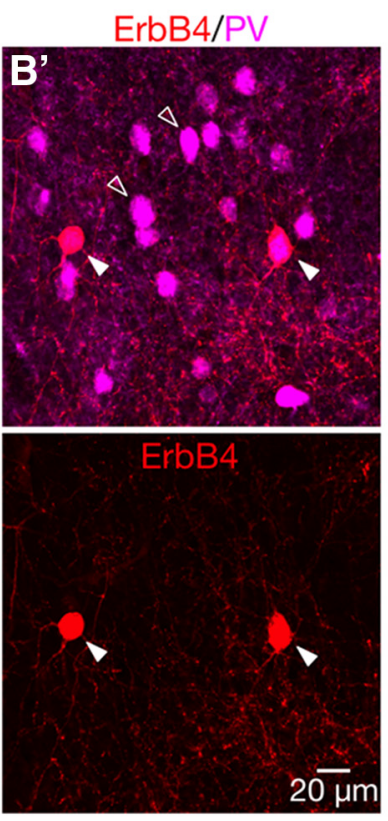

$\mathrm{PV}^{+} \mathrm{ErbB}^{+}$cells + Tam
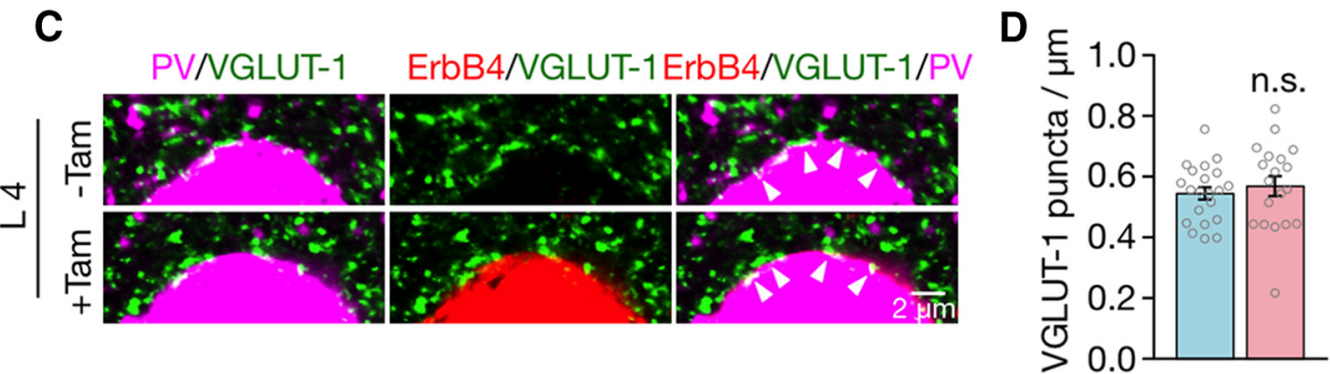

Figure 10. Non-cell-autonomous regulation by Vgat mutation of excitatory synapses onto PV ${ }^{+}$ErbB4 ${ }^{+}$interneurons. $A$, Paradigm of low-dose Tam administration and experimental timeline. $\boldsymbol{B}$, Representative coronal sections showing sparsely recombined ErbB4 ${ }^{+}$interneurons (red, labeled by tdTomato) and PV ${ }^{+}$interneurons (magenta). Higher-magnification image of the dotted rectangle $\left(\boldsymbol{B}^{\prime}\right)$ is shown on the right. $\boldsymbol{C}$, No change in excitatory synapses onto sparsely recombined PV ${ }^{+}$ErbB4 ${ }^{+}$interneurons compared with PV ${ }^{+}$interneurons without recombination. Cortical sections were stained with antibodies against PV and VGLUT-1. Shown are L4 interneurons in which ErbB4 ${ }^{+}$interneurons are labeled in red (tdTomato), VGLUT-1 punctae in green, and PV ${ }^{+}$ interneurons in magenta. D, Quantitative data in C. $n=21 \mathrm{PV}^{+}$and $n=19 \mathrm{PV}^{+}$ErbB4 ${ }^{+}$interneurons, 3 mice. n.S., Not significant. Error bars indicate SEM.

\section{Upregulated perineuronal nets (PNNs) of $\mathrm{PV}^{+} \mathrm{ErbB}^{+}$and PV-only interneurons}

The majority of fast-spiking interneurons are surrounded by PNNs, extracellular matrix structures implicated in maturation, survival, protection and plasticity of $\mathrm{PV}^{+}$interneurons (Pizzorusso et al., 2002; Gogolla et al., 2009; Wang et al., 2012). The formation of PNNs coincides with synapse maturation of $\mathrm{PV}^{+}$ interneurons (Pizzorusso et al., 2002; Wang et al., 2012) and has been implicated in protection of $\mathrm{PV}^{+}$interneurons (Gogolla et al., 2009; Cabungcal et al., 2013). Therefore, we compared PNNs between control and ErbB4-Vgat ${ }^{-1-}$ mice to see whether PNNs were affected by GABA transmission. Brain sections were incubated with Wisteria floribunda agglutinin (WFA), a lectin that binds to specific carbohydrates in PNNs, which was subsequently visualized by biotin-conjugated secondary antibody. In control mice, WFA staining was mostly around $\mathrm{PV}^{+}$ErbB4 ${ }^{+}$interneurons, whereas, a fraction of ErbB4-only and PV-only interneurons were surrounded by PNNs (Fig. 13D-F). The distribution and number of PNN-surrounded ErbB4-only cells were not altered in ErbB4-Vgat ${ }^{-1-}$ mice, indicating that PNNs of these interneurons are not regulated by Vgat ablation from ErbB4 ${ }^{+}$ interneurons (Fig. 13E). In contrast, the numbers of PNNssurrounded PV-only interneurons were increased in L4 $\left(t_{(14)}=\right.$ 3.550, $p=0.003$, post hoc power $=0.91)$ and L6 $\left(t_{(14)}=4.860\right.$, $p=0.0003$, post hoc power $=0.99)$ in ErbB4-Vgat ${ }^{-1-}$ mice (Fig. $13 F) . \mathrm{PV}^{+}$ErbB4 ${ }^{+}$cells that were surrounded by PNNs were also increased in number compared with control in cortical layers except in L5 (Fig. 13D; L2/3: $t_{(14)}=2.315, p=0.04$, post hoc power $=0.60$; $4: t_{(14)}=2.715, p=0.02$, post hoc power $=0.71$; L6: $t_{(14)}=2.660, p=0.02$, post hoc power $=0.70$ ). These changes 

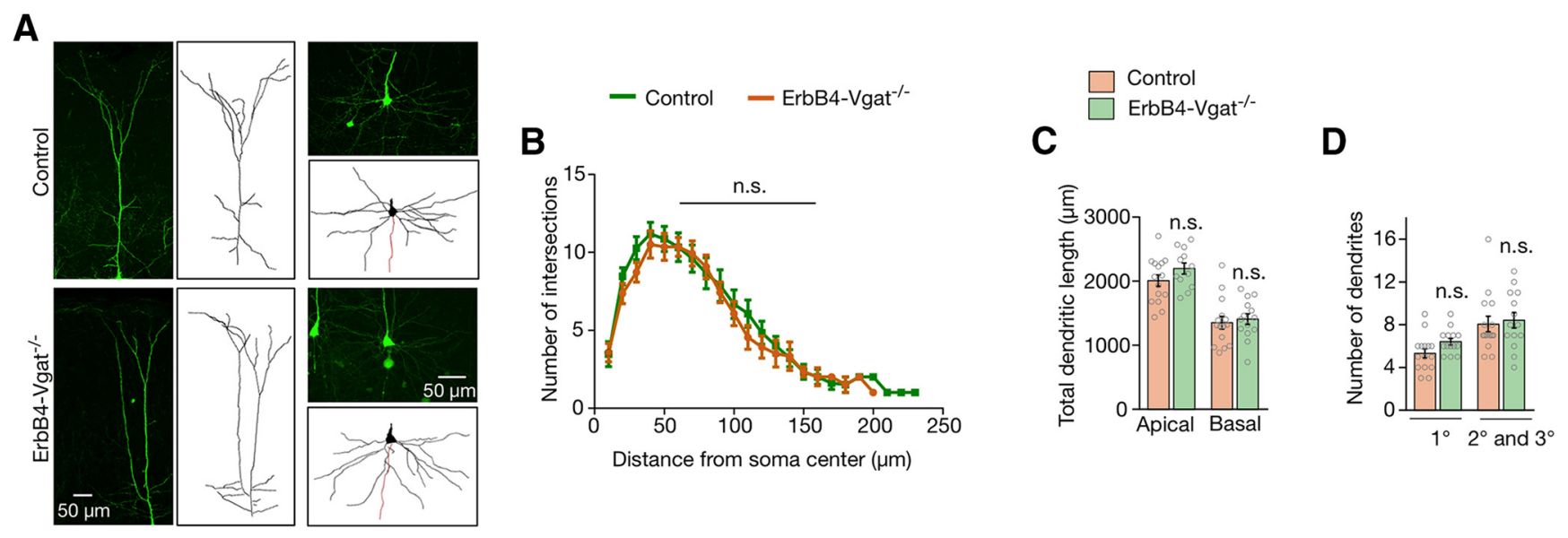

Figure 11. Normal development of pyramidal neurons in ErbB4-Vgat ${ }^{-/-}$mice. $\boldsymbol{A}$, Representative images and associated $3 \mathrm{D}$ reconstructed images of pyramidal neurons. $\boldsymbol{B}$, No change in dendritic complexity, which was revealed by Sholl analysis at $10 \mu \mathrm{m}$ concentric circles around the soma. $C$, Quantitative analysis of total dendritic length. $\boldsymbol{D}$, Quantitative analysis of dendritic branches. $\boldsymbol{B}-\boldsymbol{D}, n=15$ and 12 neurons for apical dendrites and $n=15$ and 14 neurons for basal dendrites, of control and ErbB4-Vgat ${ }^{-1-}$ mice respectively, 3 control and 4 ErbB4-Vgat ${ }^{-I-}$ mice. n.s., Not significant. Error bars indicate SEM.
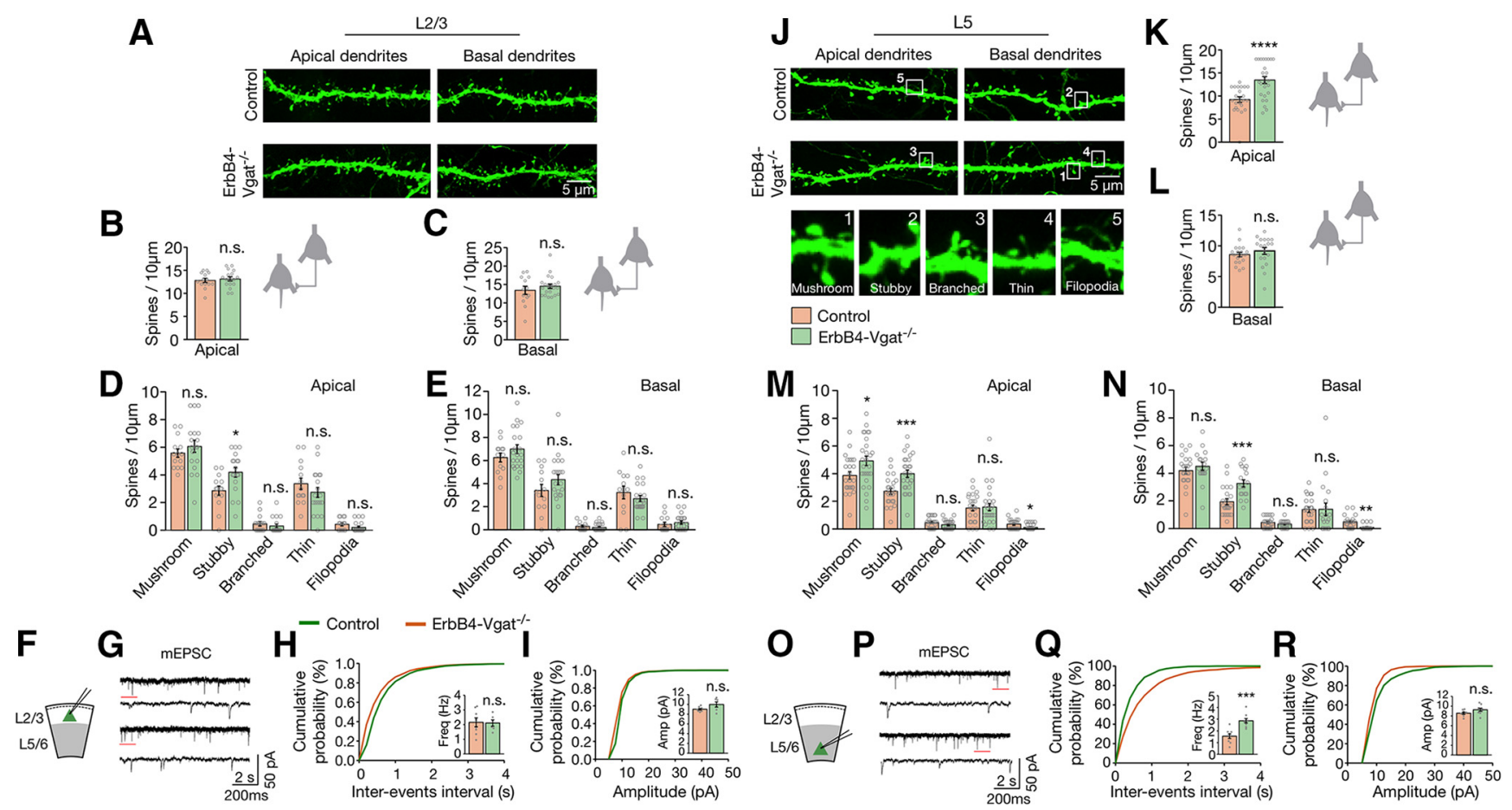

Figure 12. Increased dendritic spines of pyramidal neurons in ErbB4-Vgat ${ }^{-1-}$ mice. $A$, Representative images of apical and basal dendritic spines (genetically labeled by GFP) of L2/3 pyramidal neurons in control and ErbB4-Vgat ${ }^{-1-}$ mice. $B, C$, Similar dendritic spines of apical and basal dendrites of $L 2 / 3$ pyramidal neurons in control and ErbB4-Vgat ${ }^{-1-}$ mice $(n=12$ and 15 neurons from 3 controls and 4 ErbB4-Vgat ${ }^{-I-}$ mice, respectively, 2-3 dendritic segments per neuron). D, E, Spine subtypes distribution of L2/3 apical and basal dendrites.J, Representative images of apical and basal dendritic spines (genetically labeled by GFP) of $L 5$ pyramidal neurons in control and ErbB4-Vgat ${ }^{-1-}$ mice. Examples of different subtypes of dendritic spines in numbered boxes are shown in high magnification at the bottom. $\boldsymbol{K}, \boldsymbol{L}$, Dendritic spines of apical, but not basal, dendrites were increased ( $n=19$ and 18 neurons, in 3 controls and 4 ErbB4-Vgat ${ }^{-1-}$ mice, respectively, $2-3$ dendritic segments per neuron). $\boldsymbol{M}, \boldsymbol{N}$, Spine subtype distribution of $\mathrm{L} 5$ apical and basal dendrites. $\boldsymbol{F}, \boldsymbol{O}$, Schematics of whole-cell patch-clamp recordings of $L 2 / 3(\boldsymbol{F})$ and $L 5 / 6(\boldsymbol{O})$ pyramidal neurons in cortical slices. $\mathbf{G}, \boldsymbol{P}$, Representative traces of $\mathrm{mEPSCs}$ from $\mathrm{L} 2 / 3(\boldsymbol{G})$ and $L 5 / 6(\boldsymbol{P})$ pyramidal neurons in control and ErbB4-Vgat ${ }^{-1-}$ mice. Traces indicated by red lines are shown magnified below. $\boldsymbol{H}, \boldsymbol{I}$, no change in mEPSC frequency $(\boldsymbol{H})$ and amplitude $(\boldsymbol{I})$ in L2/3 pyramidal neurons of ErbB4-Vgat ${ }^{-I-}$ mice compared with controls. Control, $n=8$ cells, 3 mice; ErbB4-Vgat ${ }^{-l-}{ }^{,}, n=6$ cells, 3 mice. $\boldsymbol{Q}, \boldsymbol{R}$, Increased mEPSC frequency $(\boldsymbol{Q})$ and no change in mEPSC amplitude $(\boldsymbol{R})$ in $\mathrm{L} 5 / 6$ pyramidal neurons of ErbB4-Vgat ${ }^{-1-}$ mice compared with controls. Control, $n=9$ cells, 3 mice; ErbB4-Vgat ${ }^{-1-}, n=9$ cells, 3 mice. Shown are cumulative probability plots for interevent intervals and amplitudes of mEPSCs. Insets, Bar graphs for mEPSC frequency and amplitude. Error bars indicate SEM. n.s., Not significant. ${ }^{*} p<0.05$; $^{* *} p<0.01$; ${ }^{* * *} p<0.001$; ${ }^{* * * *} p<0.0001$.

were associated with an increase in WFA staining intensity (Fig. $13 C, G)$. Because there was no change in SYT2 ${ }^{+}$inhibitory synapses onto $\mathrm{PV}^{+} \mathrm{ErbB}^{+}{ }^{+}, \mathrm{PV}$-only, and ErbB4-only interneurons, this suggests that PNNs may protect SYT2 ${ }^{+}$synapses of $\mathrm{PV}^{+}$and ErbB $4^{+}$interneurons in the absence of Vgat.

\section{Discussion}

Interneurons are heterogeneous with distinct morphologies and functions (Markram et al., 2004; Klausberger et al., 2008; Le Magueresse et al., 2013; Kepecs et al., 2014). Recent genetic evidence indicates that each type of interneuron may express a distinct 
A

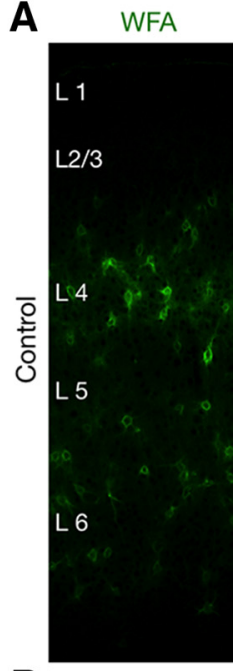

B

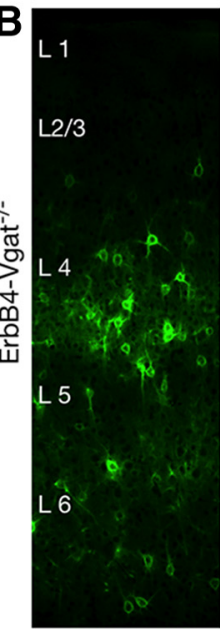

PV/WFA
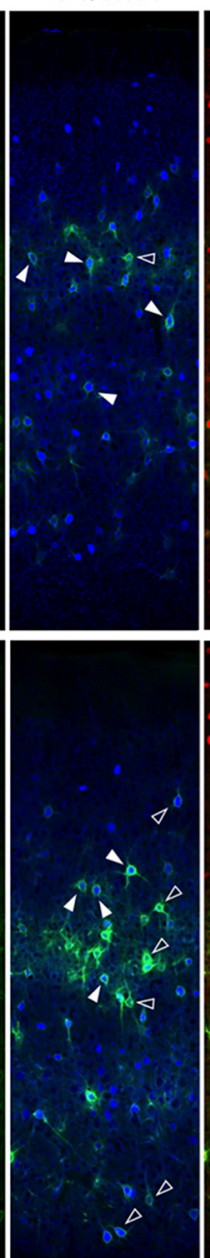

ErbB4/WFA

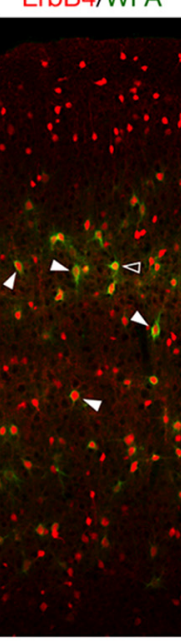

ErbB4/PV/WFA
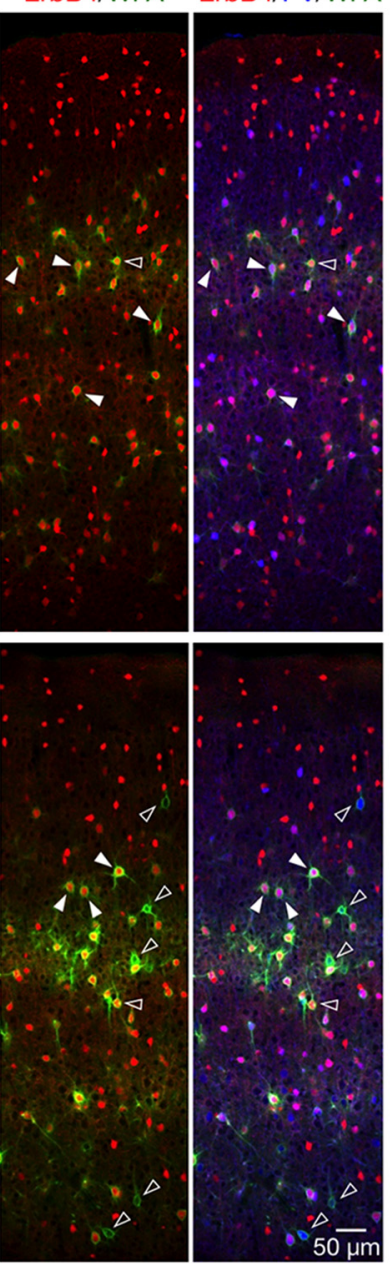

C

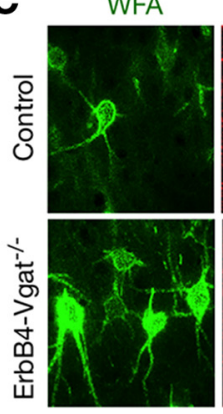

ErbB4
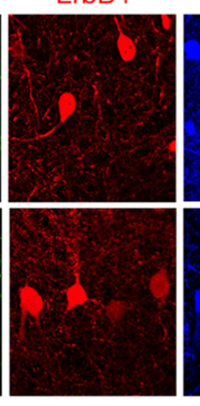

Control

D

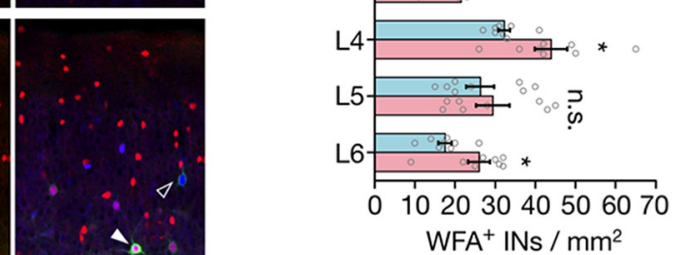

$\mathbf{F}$

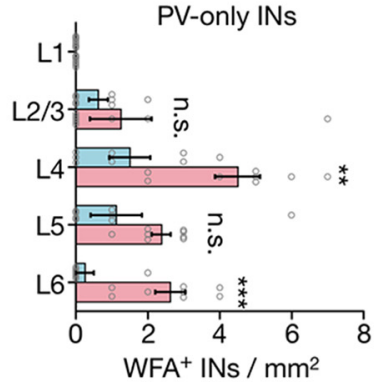

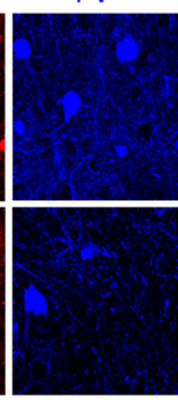

PV

ErbB4-Vgat ${ }^{-/-}$

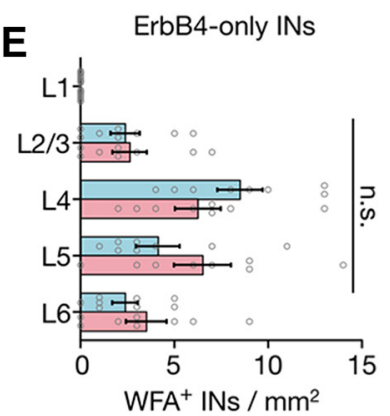

G

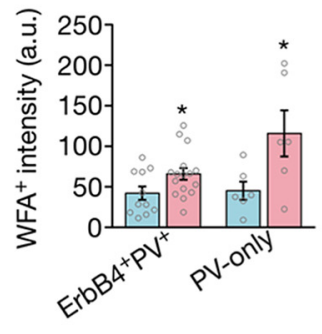

Figure 13. Upregulated perineuronal nets of $\mathrm{PV}^{+}{ }^{+}$ErbB4 ${ }^{+}$interneurons. $A, B$, Representative images of WFA-labeled PNNs (green), genetically labeled ErbB4 ${ }^{+}$interneurons (red), and coimmunofluorescence staining of PV (blue). C, Z-stacked images of ErbB4-only (red, open arrowhead), PV-only (blue, open arrowhead), or PV ${ }^{+}$ErbB4 ${ }^{+}$interneurons (closed arrowhead) surrounded by PNNs. $\boldsymbol{D}$, Increased PV ${ }^{+}$ErbB4 ${ }^{+}$interneurons in L2/3, L4, and L6 that were surrounded by PNNs. $E$, No change in numbers of ErbB4-only interneurons that were surrounded by PNNs. $F$, Increased PV-only interneurons in L4 and L6 that were surrounded by PNNs. G, Increased PNN intensity surrounding PV-only and double-positive interneurons (control, $n=8$ sections, 4 mice; ErbB4-Vgat ${ }^{-l-}, n=8$ sections, 4 mice). INs, Interneurons. Error bars indicate SEM. n.s., Not significant. ${ }^{*} p<0.05 ;{ }^{* *} p<0.01$.

combination of markers (Uematsu et al., 2008; Kubota, 2014). ErbB4 ${ }^{+}$interneurons may represent a unique class of interneurons. $\mathrm{PV}^{+}$interneurons are known to control the firing and output of pyramidal neurons, are critical for gamma oscillations and higher cognitive functions, and their abnormality has been implicated in neuropsychiatric disorders (Bartos et al., 2007; Lewis et al., 2012; Hu et al., 2014; Mei et al., 2014). PV ${ }^{+}$basket cells form axo-somatic synapses onto the somas of pyramidal neurons, whereas $\mathrm{PV}^{+}$chandelier cells innervate the AISs to form axo-axonic synapses (Kawaguchi et al., 1997; Karube et al., 2004). Using a newly identified genetic marker, ErbB4, we demonstrate that $\mathrm{PV}^{+}$interneurons are heterogeneous and can be classified into $\mathrm{PV}^{+}$ErbB4 ${ }^{+}$and PV-only cells. Our study reveals the number of axo-somatic and axo-axonic synapses formed by the different groups of interneurons in a layer-specific manner. We demonstrate how these synapses and PNNs are regulated differently by Vgat in postnatal development.

There are $\sim 65 \mathrm{PV}^{+}$axo-somatic synapses on a typical pyramidal neuron in superficial cortical layers and this number is almost doubled in L5 (Fig. 5B). Interestingly, this layer-specific distribution was not observed for $\mathrm{PV}^{+}$inhibitory synapses on
AISs: there were $\sim 10-22$ per AIS in both superficial and deep layers (Fig. 6). The increased number of axo-somatic synapses in deep layers may be due to the larger size of pyramidal neuron somas in the deep cortical layers (Custo Greig et al., 2013). Intriguingly, most of these synapses are also positive for ErbB4. Although there are ErbB4-only and PV-only interneurons in the cortex, the double-positive synapses account for 97-99\% of axo-somatic synapses and 96-99\% of axo-axonic synapses at L4-L6. These results suggest that $\mathrm{PV}^{+} \mathrm{ErbB}^{+}$interneurons preferentially innervate deep-layer pyramidal neurons, in particular to form axo-somatic synapses.

Axo-somatic and axo-axonic synapses from ErbB4-only interneurons were not as abundant in L4-L6 as other layers. Axo-axonic synapses are formed mostly, if not exclusively, by chandelier cells (Kawaguchi et al., 1997; Kubota, 2014). Previous studies indicate that $50 \%$ of these axo-axonic synapses are formed by $\mathrm{PV}^{+}$interneurons in the somatosensory cortex (Taniguchi et al., 2013). Our data suggest that ErbB4-only interneurons account for $\sim 8 \%$ in $\mathrm{L} 2 / 3$ and $\sim 2-17 \%$ in $\mathrm{L} 4-\mathrm{L} 6 \mathrm{PV}^{-}$axo-axonic synapses. Therefore, ErbB4-only interneurons may represent a unique population of interneurons. 
Although interneurons are known to synapse onto inhibitory neurons, such inhibitory synapses are not well characterized. Using the $\mathrm{PV}^{+}$terminal marker SYT2 (Sommeijer et al., 2012), we estimated for the first time the total number of $\mathrm{PV}^{+}$synapses onto $\mathrm{PV}^{+}$interneurons to be $\sim 27-40$ per soma, most of which are positive for ErbB4 (Fig. 7E). However, SYT2 ${ }^{+}$terminals onto ErbB4-only interneurons are fewer, at $18-30$ boutons per soma (Fig. $7 F$ ). These observations provide structural evidence for the notion that $\mathrm{PV}^{+}$interneurons inhibit stronger among each other, but weaker onto other types of interneurons (Pfeffer et al., 2013). Conversely, ErbB4-only interneurons and PV-only cells appear to innervate each other; some ErbB $4{ }^{+}$interneurons were positive for CR (T.W.L., unpublished data; Choi et al., 2010), a marker of inhibitory neurons targeting $\mathrm{PV}^{-}$interneurons (Pfeffer et al., 2013). Therefore, axo-somatic synapses from $\mathrm{PV}^{+} \mathrm{ErbB}^{+}$and ErbB4-only interneurons may have different roles in controlling the activity of other interneurons. Unlike inhibitory synapses onto pyramidal neurons (Fig. 5), the distribution of inhibitoryinhibitory synapses onto $\mathrm{PV}^{+} \mathrm{ErbB} 4^{+}$interneurons was similar between superficial and deep cortical layers. Interestingly, SYT2 ${ }^{+}$ inhibitory inputs onto PV-only interneurons were increased in deep cortical layers (Fig. 7G).

This study took advantage of the fact that ErbB4 is expressed in only $\sim 68 \%$ of interneurons (Bean et al., 2014). Unlike Vgatnull mice, which die between embryonic day 18 (E18) and P0, Vgat knock-out from ErbB4 ${ }^{+}$interneurons is not lethal, which enabled us to study its role in synapse development. Our Tam administration was modified from a previous study in which a single injection of Tam at $100 \mathrm{mg} / \mathrm{kg}$ was found to be effective (Taniguchi et al., 2013). In our experiments, Tam was injected three times at the same dosage to maximize the recombination efficiency. As shown in Figure 1, $I-L$, VGAT was absent in $89 \%$ of ErbB4 ${ }^{+}$boutons and, in the remaining $11 \%$ where VGAT was detected, its intensity was reduced by $84 \%$ compared with control mice. However, Vgat mutation in ErbB4 ${ }^{+}$cells had no effect on the intensity of VGAT punctae in other cells. These results demonstrate that $V g a t$ ablation was specific for ErbB4 ${ }^{+}$interneurons. The remnant amount of VGAT in ErbB4-Vgat ${ }^{-/-}$brain is likely from ErbB4 ${ }^{-}$interneurons.

This study provides in vivo genetic evidence that Vgat of from ErbB4 ${ }^{+}$interneurons regulates synapse development in the brain. Because ErbB4 ${ }^{+}$interneurons are widely distributed throughout the cortex and hippocampus, Vgat mutation in these cells is likely to reduce global GABA activity. In agreement, ErbB4-Vgat ${ }^{-1-}$ mice eventually develop seizures (Fig. 2). It is likely that overall brain activity was increased in ErbB-Vgat ${ }^{-1-}$ mice, although we focused on mice before the appearance of electrographic seizure activity (Fig. 2). Increased brain activity has been shown to promote the formation of excitatory synapses onto glutamatergic and inhibitory neurons (Chang et al., 2010; Turrigiano, 2011, 2012). Consistent with this, spine numbers and excitatory inputs onto $\mathrm{PV}^{+}$ErbB4 ${ }^{+}$interneurons are increased in ErbB4-Vgat ${ }^{-\prime-}$ mice, along with neurotransmission (Figs. 8, 12). Interestingly, GABA release from ErbB4 ${ }^{+}$interneurons is critical for $\mathrm{PV}^{+}$ $\mathrm{ErbB}^{+}{ }^{+}$axo-somatic and axo-axonic inhibitory synapses onto pyramidal somas in both superficial and deep layers, although it has no effect on the laminar distribution of ErbB4 $4^{+}, \mathrm{PV}^{+}$, or double-positive interneurons (Figs. 5, 6). This was also supported by the significant reduction in mIPSC frequency in ErbB4Vgat $^{-1-}$ mice (Fig. 5G,K). This agrees with the timing of Vgat ablation beginning at $\mathrm{P} 10$, a time after interneuron migration and before inhibitory synaptogenesis and refinement (Chattopadhyaya et al., 2004; Doischer et al., 2008; Inan et al., 2013; Tanigu- chi et al., 2013; Huang, 2014; Inan et al., 2014). PV-only and ErbB4-only axo-somatic synapses onto pyramidal neurons were not altered, indicating a specific effect of Vgat deletion on the double-positive synapses. In an early report, Cre-mediated Vgat ablation in cultured slices was shown to increase axo-somatic synapses, suggesting that GABA activity may serve as a sensor for pruning weak synapses (Wu et al., 2012). In our study, axosomatic inhibitory synapses were reduced in ErbB4-Vgat ${ }^{-1}$ mice, suggesting a positive role of GABA in inhibitory synapse formation or maintenance. Whether these effects may represent different responses to Vgat ablation at a different time point after Vgat knock-out or are due to different methodologies (single-cell knock-out in organotypic wild-type slices vs mutation in all ErbB4 ${ }^{+}$ interneurons in vivo) warrants further investigation.

Of the inhibitory synapses that are formed by $\mathrm{PV}^{+}$interneurons, $\sim 90 \%$ of them are positive for SYT2 (Sommeijer et al., 2012). At the morphological level, SYT2 ${ }^{+}$axo-somatic inhibitory synapses onto $\mathrm{PV}^{+}$ErbB4 ${ }^{+}$, ErbB4-only and PV-only interneurons were not altered by Vgat mutation (Fig. 7). However, electrophysiology revealed a reduction in mIPSC frequency in ErbB $4^{+}$interneurons in ErbB4-Vgat ${ }^{-1-}$ mice. These results could suggest that the electrophysiological method may be more sensitive than anatomic changes by staining synaptic markers. Interestingly, intact PV-PV inhibitory synapses correlated with increased level of PNNs surrounding $\mathrm{PV}^{+}$interneurons. In particular, the number of $\mathrm{PV}^{+} \mathrm{ErbB}^{+}$ and PV-only interneurons surrounded by PNNs and the intensity of PNNs were increased (Fig. 13). PNNs have been shown to promote synapse formation of $\mathrm{PV}^{+}$interneurons in response to neuronal activity (Chang et al., 2010; Pelkey et al., 2015). A parsimonious explanation of these results is that SYT2 ${ }^{+}$inhibitory synapses onto inhibitory neurons are "protected" by increased PNNs. In support of this notion was the observation that SYT2 ${ }^{-}$ inhibitory synapses (from PV-only interneurons onto ErbB4-only interneurons), most of which were not surrounded by PNNs, were reduced in ErbB4-Vgat mutant mice (Fig. 7I). Together, these observations may suggest a key, regulatory role by PNNs of inhibitory synapses onto inhibitory neurons.

\section{References}

Asada H, Kawamura Y, Maruyama K, Kume H, Ding RG, Kanbara N, Kuzume H, Sanbo M, Yagi T, Obata K (1997) Cleft palate and decreased brain gamma-aminobutyric acid in mice lacking the $67-\mathrm{kDa}$ isoform of glutamic acid decarboxylase. Proc Natl Acad Sci U S A 94:6496-6499. CrossRef Medline

Baho E, Di Cristo G (2012) Neural activity and neurotransmission regulate the maturation of the innervation field of cortical GABAergic interneurons in an age-dependent manner. J Neurosci 32:911-918. CrossRef Medline

Bartos M, Vida I, Jonas P (2007) Synaptic mechanisms of synchronized gamma oscillations in inhibitory interneuron networks. Nat Rev Neurosci 8:45-56. CrossRef Medline

Bean JC, Lin TW, Sathyamurthy A, Liu F, Yin DM, Xiong WC, Mei L (2014) Genetic labeling reveals novel cellular targets of schizophrenia susceptibility gene: distribution of GABA and non-GABA ErbB4-positive cells in adult mouse brain. J Neurosci 34:13549-13566. CrossRef Medline

Butt SJ, Sousa VH, Fuccillo MV, Hjerling-Leffler J, Miyoshi G, Kimura S, Fishell G (2008) The requirement of Nkx2-1 in the temporal specification of cortical interneuron subtypes. Neuron 59:722-732. CrossRef Medline

Cabungcal JH, Steullet P, Morishita H, Kraftsik R, Cuenod M, Hensch TK, and Do KQ (2013) Perineuronal nets protect fast-spiking interneurons against oxidative stress. Proc Natl Acad Sci U S A 110:9130-9135. CrossRef Medline

Cardin JA, Carlén M, Meletis K, Knoblich U, Zhang F, Deisseroth K, Tsai LH, Moore CI (2009) Driving fast-spiking cells induces gamma rhythm and controls sensory responses. Nature 459:663-667. CrossRef Medline

Chang MC, Park JM, Pelkey KA, Grabenstatter HL, Xu D, Linden DJ, Sutula TP, McBain CJ, Worley PF (2010) Narp regulates homeostatic scaling of 
excitatory synapses on parvalbumin-expressing interneurons. Nat Neurosci 13:1090-1097. CrossRef Medline

Chattopadhyaya B, Di Cristo G, Higashiyama H, Knott GW, Kuhlman SJ, Welker E, and Huang ZJ (2004) Experience and activity-dependent maturation of perisomatic GABAergic innervation in primary visual cortex during a postnatal critical period. J Neurosci 24:9598-9611. CrossRef Medline

Chattopadhyaya B, Di Cristo G, Wu CZ, Knott G, Kuhlman S, Fu Y, Palmiter RD, Huang ZJ (2007) GAD67-mediated GABA synthesis and signaling regulate inhibitory synaptic innervation in the visual cortex. Neuron 54: 889-903. CrossRef Medline

Chen YJ, Zhang M, Yin DM, Wen L, Ting A, Wang P, ... Gao TM (2010) ErbB4 in parvalbumin-positive interneurons is critical for neuregulin 1 regulation of long-term potentiation. Proc Natl Acad Sci U S A 107: 21818-21823. CrossRef Medline

Chen X, Nelson CD, Li X, Winters CA, Azzam R, Sousa AA, ... Reese TS (2011) PSD-95 is required to sustain the molecular organization of the postsynaptic density. J Neurosci 31:6329-6338. CrossRef Medline

Chen SX, Kim AN, Peters AJ, Komiyama T (2015) Subtype-specific plasticity of inhibitory circuits in motor cortex during motor learning. Nat Neurosci 18:1109-1115. CrossRef

Choi J, Young JA, Callaway EM (2010) Selective viral vector transduction of ErbB4 expressing cortical interneurons in vivo with a viral receptor-ligand bridge protein. Proc Natl Acad Sci U S A 107:16703-16708. CrossRef Medline

Custo Greig LF, Woodworth MB, Galazo MJ, Padmanabhan H, Macklis JD (2013) Molecular logic of neocortical projection neuron specification, development and diversity. Nat Rev Neurosci 14:755-769. CrossRef Medline

Del Pino I, García-Frigola C, Dehorter N, Brotons-Mas JR, Alvarez-Salvado E, Martínez de Lagrán M, Ciceri G, Gabaldón MV, Moratal D, Dierssen M, Canals S, Marín O, Rico B (2013) Erbb4 deletion from fast-spiking interneurons causes schizophrenia-like phenotypes. Neuron 79:11521168. CrossRef Medline

Doischer D, Hosp JA, Yanagawa Y, Obata K, Jonas P, Vida I, Bartos M (2008) Postnatal differentiation of basket cells from slow to fast signaling devices. J Neurosci 28:12956-12968. CrossRef Medline

Essrich C, Lorez M, Benson JA, Fritschy JM, Lüscher B (1998) Postsynaptic clustering of major GABAA receptor subtypes requires the gamma 2 subunit and gephyrin. Nat Neurosci 1:563-571. CrossRef Medline

Faul F, Erdfelder E, Buchner A, Lang AG (2009) Statistical power analyses using $G^{\star}$ Power 3.1: tests for correlation and regression analyses. Behav Res Methods 41:1149-1160. CrossRef Medline

Fazzari P, Paternain AV, Valiente M, Pla R, Luján R, Lloyd K, Lerma J, Marín O, Rico B (2010) Control of cortical GABA circuitry development by Nrg1 and ErbB4 signalling. Nature 464:1376-1380. CrossRef Medline

Feng G, Mellor RH, Bernstein M, Keller-Peck C, Nguyen QT, Wallace M, Nerbonne JM, Lichtman JW, Sanes JR (2000) Imaging neuronal subsets in transgenic mice expressing multiple spectral variants of GFP. Neuron 28:41-51. CrossRef Medline

Fiala JC (2005) Reconstruct: a free editor for serial section microscopy. J Microsc 218:52-61. CrossRef Medline

Flames N, Long JE, Garratt AN, Fischer TM, Gassmann M, Birchmeier C, Lai C, Rubenstein JL, Marín O (2004) Short- and long-range attraction of cortical GABAergic interneurons by neuregulin-1. Neuron 44:251-261. CrossRef Medline

Fon EA, Edwards RH (2001) Molecular mechanisms of neurotransmitter release. Muscle Nerve 24:581-601. CrossRef Medline

Gelman DM, Marín O (2010) Generation of interneuron diversity in the mouse cerebral cortex. Eur J Neurosci 31:2136-2141. CrossRef Medline

Gogolla N, Caroni P, Lüthi A, Herry C (2009) Perineuronal nets protect fear memories from erasure. Science 325:1258-1261. CrossRef Medline

Gonchar Y, Wang Q, Burkhalter A (2007) Multiple distinct subtypes of GABAergic neurons in mouse visual cortex identified by triple immunostaining. Front Neuroanat 1:3. CrossRef Medline

Homanics GE, DeLorey TM, Firestone LL, Quinlan JJ, Handforth A, Harrison NL, Krasowski MD, Rick CE, Korpi ER, Mäkelä R, Brilliant MH, Hagiwara N, Ferguson C, Snyder K, Olsen RW (1997) Mice devoid of gamma-aminobutyrate type A receptor beta3 subunit have epilepsy, cleft palate, and hypersensitive behavior. Proc Natl Acad Sci U S A 94:41434148. CrossRef Medline

Huang ZJ (2014) Toward a genetic dissection of cortical circuits in the mouse. Neuron 83:1284-1302. CrossRef Medline

Huang ZJ, Di Cristo G, Ango F (2007) Development of GABA innervation in the cerebral and cerebellar cortices. Nat Rev Neurosci 8:673-686. CrossRef Medline

$\mathrm{Hu} \mathrm{H}$, Gan J, Jonas P (2014) Interneurons. Fast-spiking, parvalbumin $\left({ }^{+}\right)$ GABAergic interneurons: from cellular design to microcircuit function. Science 345:1255263. CrossRef Medline

Inan M, Blázquez-Llorca L, Merchán-Pérez A, Anderson SA, DeFelipe J, Yuste R (2013) Dense and overlapping innervation of pyramidal neurons by chandelier cells. J Neurosci 33:1907-1914. CrossRef Medline

Inan M, Anderson SA (2014) The chandelier cell, form and function. Curr Opin Neurobiol 26:142-148. CrossRef Medline

Isaacson JS, Scanziani M (2011) How inhibition shapes cortical activity. Neuron 72:231-243. CrossRef Medline

Jenkins SM, Bennett V (2001) Ankyrin-G coordinates assembly of the spectrin-based membrane skeleton, voltage-gated sodium channels, and L1 CAMs at Purkinje neuron initial segments. J Cell Biol 155:739-746. CrossRef Medline

Ji F, Kanbara N, Obata K (1999) GABA and histogenesis in fetal and neonatal mouse brain lacking both the isoforms of glutamic acid decarboxylase. Neurosci Res 33:187-194. CrossRef Medline

Jiang X, Wang G, Lee AJ, Stornetta RL, Zhu JJ (2013) The organization of two new cortical interneuronal circuits. Nat Neurosci 16:210-218. CrossRef Medline

Kanaani J, Kolibachuk J, Martinez H, Baekkeskov S (2010) Two distinct mechanisms target GAD67 to vesicular pathways and presynaptic clusters. J Cell Biol 190:911-925. CrossRef Medline

Kaneko T, Fujiyama F (2002) Complementary distribution of vesicular glutamate transporters in the central nervous system. Neurosci Res 42:243250. CrossRef Medline

Karube F, Kubota Y, Kawaguchi Y (2004) Axon branching and synaptic bouton phenotypes in GABAergic nonpyramidal cell subtypes. J Neurosci 24:2853-2865. CrossRef Medline

Kasugai Y, Swinny JD, Roberts JD, Dalezios Y, Fukazawa Y, Sieghart W, Shigemoto R, Somogyi P (2010) Quantitative localisation of synaptic and extrasynaptic GABAA receptor subunits on hippocampal pyramidal cells by freeze-fracture replica immunolabelling. Eur J Neurosci 32:18681888. CrossRef Medline

Kawaguchi Y, Kubota Y (1997) GABAergic cell subtypes and their synaptic connections in rat frontal cortex. Cereb Cortex 7:476-486. CrossRef Medline

Kepecs A, Fishell G (2014) Interneuron cell types are fit to function. Nature 505:318-326. CrossRef Medline

Kilb W (2012) Development of the GABAergic system from birth to adolescence. Neuroscientist 18:613-630. CrossRef Medline

Klausberger T, Somogyi P (2008) Neuronal diversity and temporal dynamics: the unity of hippocampal circuit operations. Science 321:53-57. CrossRef Medline

Kobayashi Y, Ye Z, Hensch TK (2015) Clock genes control cortical critical period timing. Neuron 86:264-275. CrossRef Medline

Krivosheya D, Tapia L, Levinson JN, Huang K, Kang Y, Hines R, Ting AK, Craig AM, Mei L, Bamji SX, El-Husseini A (2008) ErbB4-neuregulin signaling modulates synapse development and dendritic arborization through distinct mechanisms. J Biol Chem 283:32944-32956. CrossRef Medline

Kubota Y (2014) Untangling GABAergic wiring in the cortical microcircuit. Curr Opin Neurobiol 26:7-14. CrossRef Medline

Le Magueresse C, Monyer H (2013) GABAergic interneurons shape the functional maturation of the cortex. Neuron 77:388-405. CrossRef Medline

Lewis DA (2014) Inhibitory neurons in human cortical circuits: substrate for cognitive dysfunction in schizophrenia. Curr Opin Neurobiol 26:2226. CrossRef Medline

Lewis DA, Curley AA, Glausier JR, Volk DW (2012) Cortical parvalbumin interneurons and cognitive dysfunction in schizophrenia. Trends Neurosci 35:57-67. CrossRef Medline

Liodis P, Denaxa M, Grigoriou M, Akufo-Addo C, Yanagawa Y, Pachnis V (2007) Lhx6 activity is required for the normal migration and specification of cortical interneuron subtypes. J Neurosci 27:3078-3089. CrossRef Medline

Luhmann HJ, Fukuda A, Kilb W (2015) Control of cortical neuronal migration by glutamate and GABA. Front Cell Neurosci 9:4. CrossRef Medline Lu Y, Sun XD, Hou FQ, Bi LL, Yin DM, Liu F, Chen YJ, Bean JC, Jiao HF, Liu X, Li BM, Xiong WC, Gao TM, Mei L (2014) Maintenance of GABAergic 
activity by neuregulin 1-ErbB4 in amygdala for fear memory. Neuron 84:835-846. CrossRef Medline

Madisen L, Zwingman TA, Sunkin SM, Oh SW, Zariwala HA, Gu H, Ng LL, Palmiter RD, Hawrylycz MJ, Jones AR, Lein ES, Zeng H (2010) A robust and high-throughput Cre reporting and characterization system for the whole mouse brain. Nat Neurosci 13:133-140. CrossRef Medline

Marin O (2012) Interneuron dysfunction in psychiatric disorders. Nat Rev Neurosci 13:107-120. CrossRef Medline

Marin O (2013) Cellular and molecular mechanisms controlling the migration of neocortical interneurons. Eur J Neurosci 38:2019-2029. CrossRef Medline

Markram H, Toledo-Rodriguez M, Wang Y, Gupta A, Silberberg G, Wu C (2004) Interneurons of the neocortical inhibitory system. Nat Rev Neurosci 5:793-807. CrossRef Medline

Mei L, Nave KA (2014) Neuregulin-ERBB signaling in the nervous system and neuropsychiatric diseases. Neuron 83:27-49. CrossRef Medline

Miceli S, Nadif Kasri N, Joosten J, Huang C, Kepser L, Proville R, Selten MM, van Eijs F, Azarfar A, Homberg JR, Celikel T, Schubert D (2017) Reduced inhibition within layer IV of Sert knock-out rat barrel cortex is associated with faster sensory integration. Cereb Cortex 27:933-949. CrossRef Medline

Minelli A, Alonso-Nanclares L, Edwards RH, DeFelipe J, Conti F (2003) Postnatal development of the vesicular GABA transporter in rat cerebral cortex. NeuroScience 117:337-346. CrossRef Medline

Miyoshi G, Fishell G (2011) GABAergic interneuron lineages selectively sort into specific cortical layers during early postnatal development. Cereb Cortex 21:845-852. CrossRef Medline

Mullen RJ, Buck CR, Smith AM (1992) NeuN, a neuronal specific nuclear protein in vertebrates. Development 116:201-211. Medline

Okaty BW, Miller MN, Sugino K, Hempel CM, Nelson SB (2009) Transcriptional and electrophysiological maturation of neocortical fastspiking GABAergic interneurons. J Neurosci 29:7040-7052. CrossRef Medline

Owens DF, Kriegstein AR (2002) Is there more to GABA than synaptic inhibition? Nat Rev Neurosci 3:715-727. CrossRef Medline

Packer AM, Yuste R (2011) Dense, unspecific connectivity of neocortical parvalbumin-positive interneurons: a canonical microcircuit for inhibition? J Neurosci 31:13260-13271. CrossRef Medline

Panzanelli P, Gunn BG, Schlatter MC, Benke D, Tyagarajan SK, Scheiffele P, Belelli D, Lambert JJ, Rudolph U, Fritschy JM (2011) Distinct mechanisms regulate GABAA receptor and gephyrin clustering at perisomatic and axo-axonic synapses on CAl pyramidal cells. J Physiol 589:49594980. CrossRef Medline

Pelkey KA, Barksdale E, Craig MT, Yuan X, Sukumaran M, Vargish GA, Mitchell RM, Wyeth MS, Petralia RS, Chittajallu R, Karlsson RM, Cameron HA, Murata Y, Colonnese MT, Worley PF, McBain CJ (2015) Pentraxins coordinate excitatory synapse maturation and circuit integration of parvalbumin interneurons. Neuron 85:1257-1272. CrossRef Medline

Peng H, Ruan Z, Long F, Simpson JH, Myers EW (2010) V3D enables realtime $3 \mathrm{D}$ visualization and quantitative analysis of large-scale biological image data sets. Nat Biotechnol 28:348-353. CrossRef Medline

Pfeffer CK, Xue M, He M, Huang ZJ, Scanziani M (2013) Inhibition of inhibition in visual cortex: the logic of connections between molecularly distinct interneurons. Nat Neurosci 16:1068-1076. CrossRef Medline

Pizzorusso T, Medini P, Berardi N, Chierzi S, Fawcett JW, Maffei L (2002) Reactivation of ocular dominance plasticity in the adult visual cortex. Science 298:1248-1251. CrossRef Medline

Rakic P, Bourgeois JP, Eckenhoff MF, Zecevic N, Goldman-Rakic PS (1986) Concurrent overproduction of synapses in diverse regions of the primate cerebral cortex. Science 232:232-235. CrossRef Medline

Saito K, Kakizaki T, Hayashi R, Nishimaru H, Furukawa T, Nakazato Y, Takamori S, Ebihara S, Uematsu M, Mishina M, Miyazaki J, Yokoyama M, Konishi S, Inoue K, Fukuda A, Fukumoto M, Nakamura K, Obata K, Yanagawa Y (2010) The physiological roles of vesicular GABA transporter during embryonic development: a study using knock-out mice. Mol Brain 3:40. CrossRef Medline

Schindelin J, Arganda-Carreras I, Frise E, Kaynig V, Longair M, Pietzsch T, Preibisch S, Rueden C, Saalfeld S, Schmid B, Tinevez JY, White DJ, Hartenstein V, Eliceiri K, Tomancak P, Cardona A (2012) Fiji: an open- source platform for biological-image analysis. Nat Methods 9:676-682. CrossRef Medline

Sohal VS, Zhang F, Yizhar O, Deisseroth K (2009) Parvalbumin neurons and gamma rhythms enhance cortical circuit performance. Nature 459: 698-702. CrossRef Medline

Sommeijer JP, Levelt CN (2012) Synaptotagmin-2 is a reliable marker for parvalbumin positive inhibitory boutons in the mouse visual cortex. PLoS One 7:e35323. CrossRef Medline

Somogyi P (1977) A specific 'axo-axonal' interneuron in the visual cortex of the rat. Brain Res 136:345-350. CrossRef Medline

Somogyi P, Freund TF, Cowey A (1982) The axo-axonic interneuron in the cerebral cortex of the rat, cat and monkey. NeuroScience 7:2577-2607. CrossRef Medline

Taniguchi H, Lu J, Huang ZJ (2013) The spatial and temporal origin of chandelier cells in mouse neocortex. Science 339:70-74. CrossRef Medline

Ting AK, Chen Y, Wen L, Yin DM, Shen C, Tao Y, Liu X, Xiong WC, Mei L (2011) Neuregulin 1 promotes excitatory synapse development and function in GABAergic interneurons. J Neurosci 31:15-25. CrossRef Medline

Tong Q, Ye CP, Jones JE, Elmquist JK, Lowell BB (2008) Synaptic release of GABA by AgRP neurons is required for normal regulation of energy balance. Nat Neurosci 11:998-1000. CrossRef Medline

Tremblay R, Lee S, Rudy B (2016) GABAergic interneurons in the neocortex: from cellular properties to circuits. Neuron 91:260-292. CrossRef Medline

Turrigiano G (2011) Too many cooks? Intrinsic and synaptic homeostatic mechanisms in cortical circuit refinement. Annu Rev Neurosci 34:89_ 103. CrossRef Medline

Turrigiano G (2012) Homeostatic synaptic plasticity: local and global mechanisms for stabilizing neuronal function. Cold Spring Harb Perspect Biol 4:a005736. CrossRef Medline

Uematsu M, Hirai Y, Karube F, Ebihara S, Kato M, Abe K, Obata K, Yoshida S, Hirabayashi M, Yanagawa Y, Kawaguchi Y (2008) Quantitative chemical composition of cortical GABAergic neurons revealed in transgenic venus-expressing rats. Cereb Cortex 18:315-330. CrossRef Medline

Wang D, Fawcett J (2012) The perineuronal net and the control of CNS plasticity. Cell Tissue Res 349:147-160. CrossRef Medline

Wen L, Lu YS, Zhu XH, Li XM, Woo RS, Chen YJ, Yin DM, Lai C, Terry AV Jr, Vazdarjanova A, Xiong WC, Mei L (2010) Neuregulin 1 regulates pyramidal neuron activity via ErbB4 in parvalbumin-positive interneurons. Proc Natl Acad Sci U S A 107:1211-1216. CrossRef Medline

Wojcik SM, Katsurabayashi S, Guillemin I, Friauf E, Rosenmund C, Brose N, Rhee JS (2006) A shared vesicular carrier allows synaptic corelease of GABA and glycine. Neuron 50:575-587. CrossRef Medline

Woo RS, Li XM, Tao Y, Carpenter-Hyland E, Huang YZ, Weber J, Neiswender H, Dong XP, Wu J, Gassmann M, Lai C, Xiong WC, Gao TM, Mei L (2007) Neuregulin-1 enhances depolarization-induced GABA release. Neuron 54:599-610. CrossRef Medline

Wu X, Fu Y, Knott G, Lu J, Di Cristo G, Huang ZJ (2012) GABA signaling promotes synapse elimination and axon pruning in developing cortical inhibitory interneurons. J Neurosci 32:331-343. CrossRef Medline

Xu X, Roby KD, Callaway EM (2010) Immunochemical characterization of inhibitory mouse cortical neurons: three chemically distinct classes of inhibitory cells. J Comp Neurol 518:389-404. CrossRef Medline

Yau HJ, Wang HF, Lai C, Liu FC (2003) Neural development of the neuregulin receptor ErbB4 in the cerebral cortex and the hippocampus: preferential expression by interneurons tangentially migrating from the ganglionic eminences. Cereb Cortex 13:252-264. CrossRef Medline

Ye Z, Mostajo-Radji MA, Brown JR, Rouaux C, Tomassy GS, Hensch TK, Arlotta P (2015) Instructing perisomatic inhibition by direct lineage reprogramming of neocortical projection neurons. Neuron 88:475-483. CrossRef Medline

Yin DM, Chen YJ, Lu YS, Bean JC, Sathyamurthy A, Shen C, Liu X, Lin TW, Smith CA, Xiong WC, Mei L (2013) Reversal of behavioral deficits and synaptic dysfunction in mice overexpressing neuregulin 1 . Neuron 78 : 644-657. CrossRef Medline

Yin DM, Sun XD, Bean JC, Lin TW, Sathyamurthy A, Xiong WC, Gao TM, Chen YJ, Mei L (2013) Regulation of spine formation by ErbB4 in PVpositive interneurons. J Neurosci 33:19295-19303. CrossRef Medline 